\title{
Wind- versus Eddy-Forced Regional Sea Level Trends and Variability in the North Pacific Ocean
}

\author{
Bo QIU AND SHUIMING CHEN \\ Department of Oceanography, University of Hawai'i at Mānoa, Honolulu, Hawaii \\ LIXIN WU \\ Physical Oceanography Laboratory, Ocean University of China, Qingdao, China \\ SHINICHIRO KIDA \\ Application Laboratory, JAMSTEC, Yokohama, Japan
}

(Manuscript received 8 July 2014, in final form 25 September 2014)

\begin{abstract}
Regional sea level trend and variability in the Pacific Ocean have often been considered to be induced by low-frequency surface wind changes. This study demonstrates that significant sea level trend and variability can also be generated by eddy momentum flux forcing due to time-varying instability of the background oceanic circulation. Compared to the broad gyre-scale wind-forced variability, the eddy-forced sea level changes tend to have subgyre scales and, in the North Pacific Ocean, they are largely confined to the Kuroshio Extension region $\left(30^{\circ}-40^{\circ} \mathrm{N}, 140^{\circ}-175^{\circ} \mathrm{E}\right)$ and the Subtropical Countercurrent (STCC) region $\left(18^{\circ}-28^{\circ} \mathrm{N}\right.$, $130^{\circ}-175^{\circ} \mathrm{E}$ ). Using a two-layer primitive equation model driven by the ECMWF wind stress data and the eddy momentum fluxes specified by the AVISO sea surface height anomaly data, the relative importance of the wind- and eddy-forced regional sea level trends in the past two decades is quantified. It is found that the increasing (decreasing) trend south (north) of the Kuroshio Extension is due to strengthening of the regional eddy forcing over the past two decades. On the other hand, the decreasing (increasing) sea level trend south (north) of the STCC is caused by the decadal weakening of the regional eddy momentum flux forcing. These decadal eddy momentum flux changes are caused by the background Kuroshio Extension and STCC changes in connection with the Pacific decadal oscillation (PDO) wind pattern shifting from a positive to a negative phase over the past two decades.
\end{abstract}

\section{Introduction}

Over the past two decades, the globally averaged sea level has risen at an accelerated rate of $3.2 \mathrm{~mm} \mathrm{yr}^{-1}$ and many studies of interdisciplinary nature have increased our understanding of this rate, including the budget of various contributing components (see Bindoff et al. 2007; Church et al. 2013, and references therein). On the regional basis, however, the sea level trends can deviate from the global mean value significantly (e.g., Cazenave and Llovel 2010; Stammer et al. 2013). As shown in Fig. 1, the regional sea level trends can exceed by twice

Corresponding author address: Dr. Bo Qiu, Department of Oceanography, University of Hawai‘i at Mānoa, 1000 Pope Road, Honolulu, HI 96822.

E-mail: bo@soest.hawaii.edu the $3.2 \mathrm{~mm} \mathrm{yr}^{-1}$ value at various locations and their spatial patterns contain signals over a wide range of length scales. In the North Pacific Ocean, for example, relatively broad-scale regional sea level rises (drops) are detected in the tropical regions and in the central (eastern) extratropical regions. In contrast, the regional sea level trend signals have generally smaller meridional spatial scales in the western subtropical and subarctic regions. For the coastal regions surrounding the Pacific basin where human activities are concentrated and where landmass erosion and inundation can exert most impact, it is the regional sea level variability that is of paramount importance.

To clarify the dynamical causes behind the regional sea level trends in the tropical Pacific Ocean, many data analyses and numerical modeling studies have related the sea level rise in the western basin and drop in the 


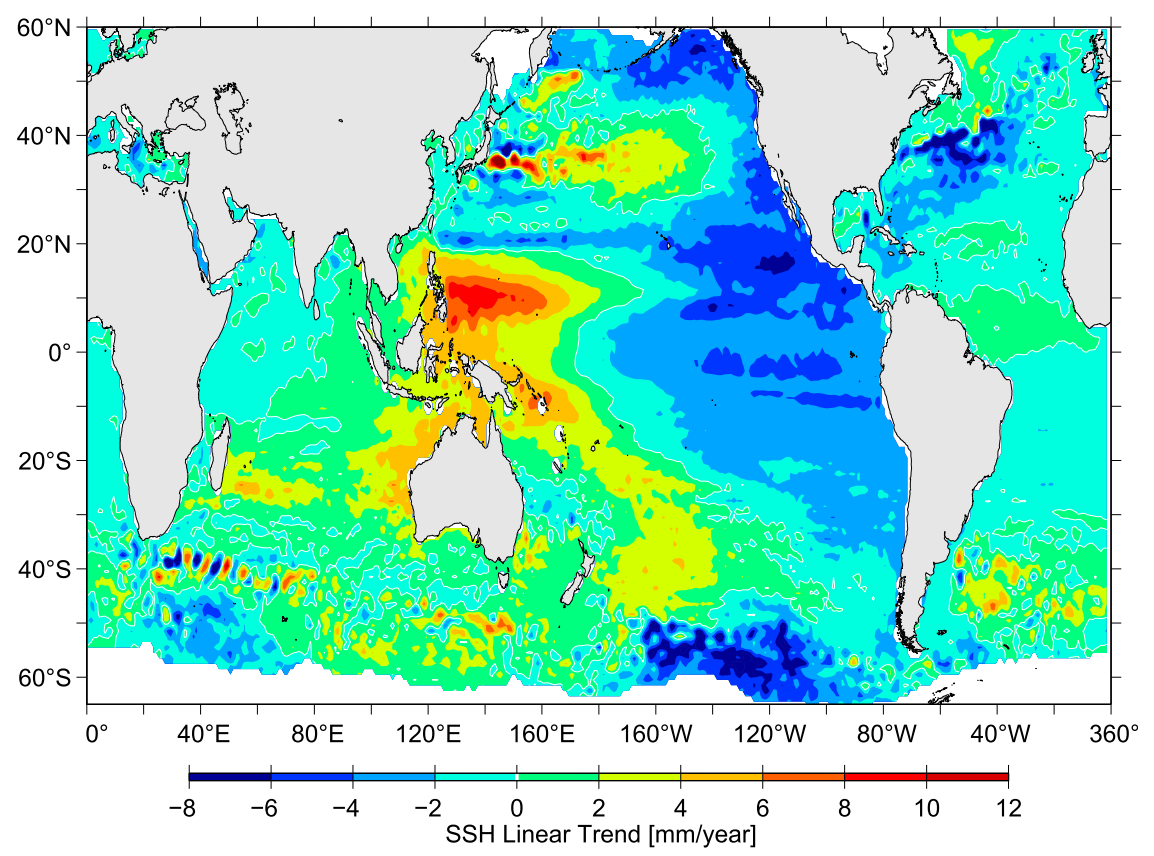

FIG. 1. Linear trend in sea level from satellite altimeter measurements of October 1992December 2013. Notice that the global mean value of $3.2 \mathrm{~mm} \mathrm{yr}^{-1}$ has been subtracted out to emphasize the regional sea level trend signals. White contours denote a zero relative trend.

eastern basin to the strengthening of the trade winds across the tropical Pacific Ocean over the past two decades (Köhl and Stammer 2008; Timmermann et al. 2010; Feng et al. 2010; Merrifield and Maltrud 2011; Qiu and Chen 2012). With regard to the regional sea level changes in the extratropical North Pacific, the lowfrequency changes in the surface wind stress field have also been considered a main driver in determining the regional sea level trends and variability in the western subarctic gyre, the Alaska gyre, the Kuroshio Extension, and off the North America continent (e.g., Qiu 2002; Cummins and Lagerloef 2004; Qiu and Chen 2005; Yasuda and Sakurai 2006; Bromirski et al. 2011; Sasaki et al. 2014). It is worth emphasizing that away from the coastal orography, the surface wind stress field has generally large spatial scales. As such, the wind-forced regional sea level variability has necessarily broad spatial scales that are found in the extratropical central and eastern North Pacific Ocean. To properly understand the smaller-scale regional sea level trends detected in the western North Pacific Ocean (see Fig. 2b), we need to explore the physical mechanisms beyond the direct wind forcing.

An indirect way the large-scale surface wind changes affect the regional sea level variability is through modulation of the strength of the ocean circulation gyres and its dynamical stability (see Fig. 2a for the wind-driven subtropical and subarctic gyres in the North Pacific Ocean). Because of the underlying ocean dynamics, some parts of the wind-driven gyres are susceptible to dynamical instabilities. In the extratropical North Pacific Ocean, the unstable regions are largely confined to two latitudinal bands (Fig. 3a). The first band is located along $32^{\circ}-38^{\circ} \mathrm{N}$, where the western boundary current Kuroshio enters the open North Pacific Ocean basin and becomes a free, baroclinic unstable jet known as the Kuroshio Extension. The second band of high mesoscale eddy variability appears between Taiwan and Hawaii along $18^{\circ}-$ $28^{\circ} \mathrm{N}$. The high mesoscale eddy variability along this band is due to the presence of the wind-driven Subtropical Countercurrent (STCC) whose eastward shear relative to the underlying, westward-flowing North Equatorial Current (NEC) provides the energy source for the regional baroclinic instability [see Qiu and Chen (2013) and references therein]. As the large-scale surface wind stress field fluctuates in time, the baroclinicity of the Kuroshio Extension jet and the STCC changes, affecting the intensity of their instabilities and the energy level of regional mesoscale eddies. Indeed, significant changes in the level of eddy kinetic energy have been detected over the past two decades along the Kuroshio Extension and STCC regions in the North Pacific Ocean (Fig. 3b). Dynamically, it is well known that the eddy momentum flux forcing can feedback to modify the time-mean circulation and its geostrophically balanced sea level (e.g., Rhines and Holland 1979; Greatbatch et al. 2010a,b; Qiu and Chen 2010a; Penduff et al. 2011). As the energy level of mesoscale 
(a) Climatological Mean SSH Field

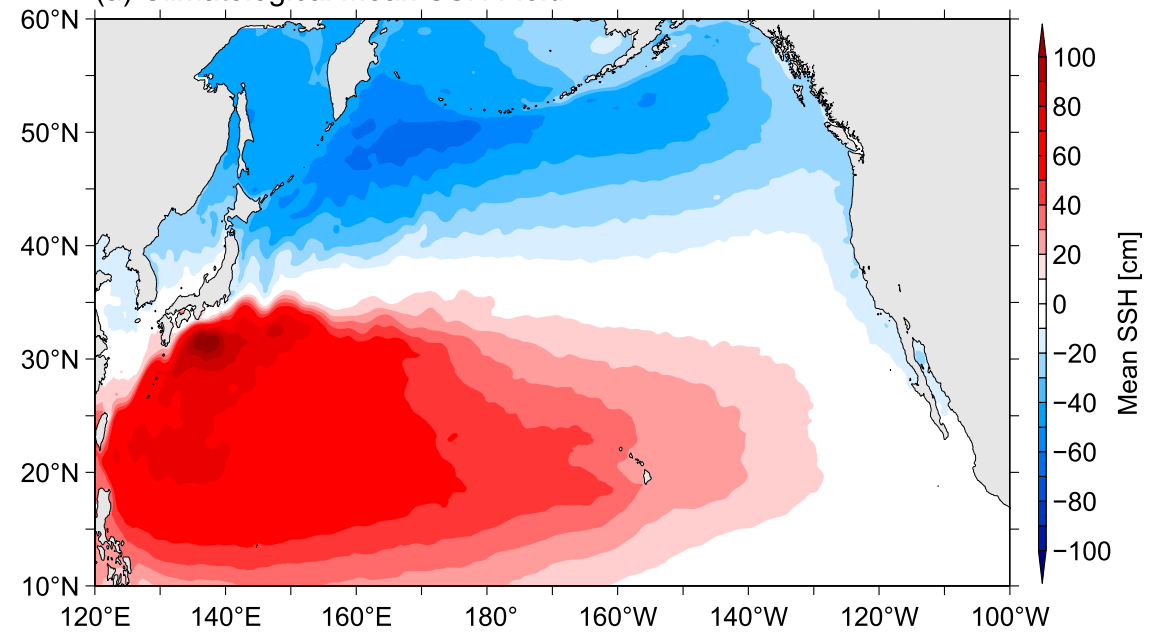

(b) Observed Sea Level Trend

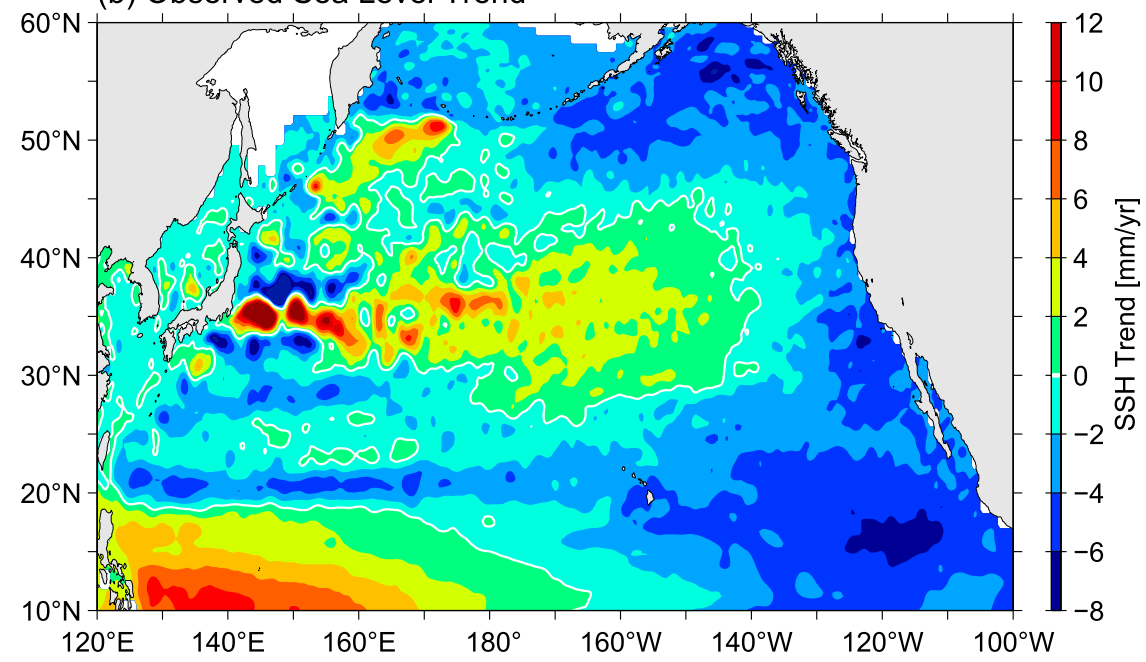

FIG. 2. (a) Mean SSH field in the North Pacific Ocean from Rio et al. (2011). Values are relative to a constant of $70 \mathrm{~cm}$. (b) As in Fig. 1, but for the linear sea level trend in the North Pacific Ocean.

eddies alters with time, it is natural to expect the eddyforced mean circulation and sea level would also change.

The first objective of this study is to quantify the extent to which the time-varying eddy momentum flux forcing, such as that detected over the past two decades by satellite altimeters, affects the regional sea level trend signals shown in Fig. 2b in the extratropical North Pacific Ocean. In particular, we are interested in the eddy-forced sea level variability in the context of the regional sea level trends forced directly by the time-varying wind stresses. With the aid of a two-layer ocean dynamical framework, our second objective is to clarify the processes that control the observed wind- and eddy-forced regional sea level trends. The importance of the large-scale atmospheric forcing relating to the Pacific decadal oscillation (PDO; Mantua et al. 1997) will be emphasized.
The paper is organized as follows. After describing the observed sea surface height and wind stress datasets in section 2, we detail in section 3 the two-layer primitive equation model used in this study to quantify the windversus eddy-forced regional sea level changes. Section 4 presents the modeled sea level trend signals under the scenarios of wind, eddy, and combined wind and eddy forcings, respectively. In section 5, we explore the dynamical processes underlying the wind- and eddy-forced sea level variability and summarize the results from the present study.

\section{Observational datasets}

To quantify the modeled sea level variability under different forcing scenarios and to specify the external 
(a) EKE

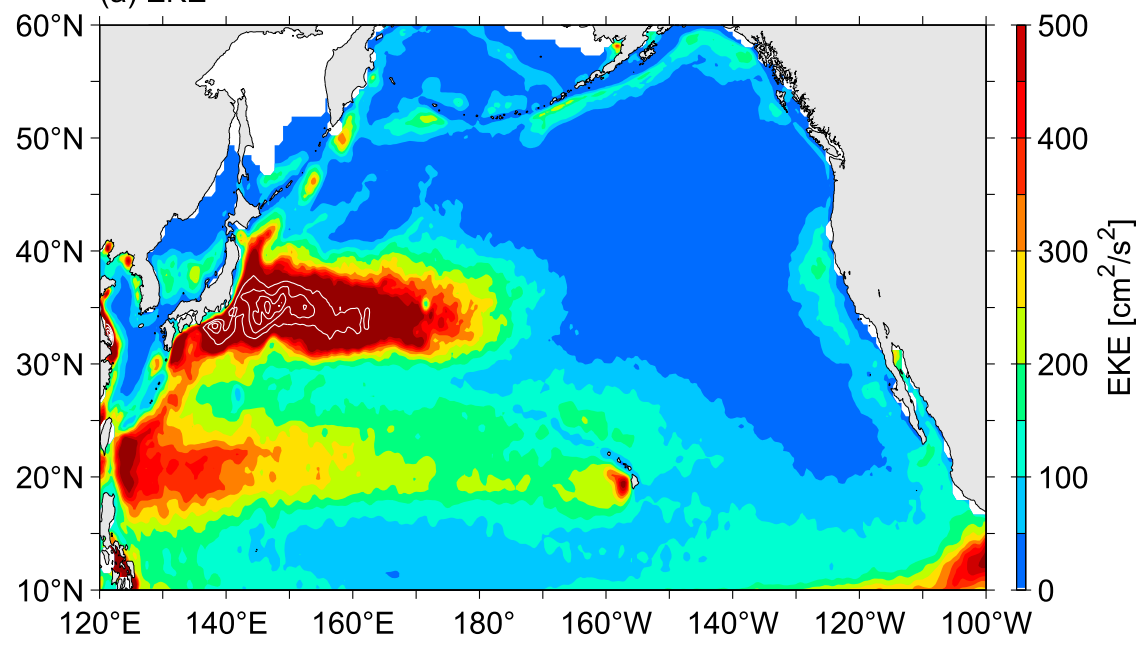

(b) EKE Trend

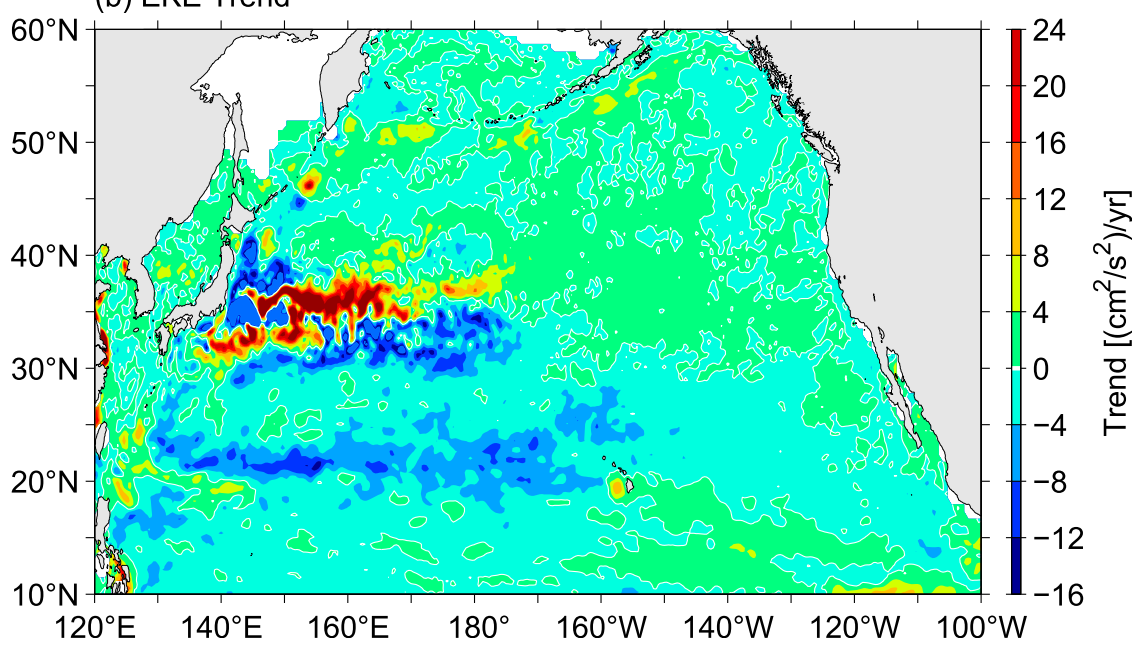

FIG. 3. (a) Distribution of eddy kinetic energy in the North Pacific Ocean inferred from the AVISO SSH anomaly data. Thin white contours have an interval of $500 \mathrm{~cm}^{2} \mathrm{~s}^{-2}$ starting from $1000 \mathrm{~cm}^{2} \mathrm{~s}^{-2}$. (b) Linear trend of EKE in the North Pacific Ocean. White contours denote a zero trend.

eddy forcing field, we use in this study the global SSH anomaly dataset produced by SSALTO/Data Unification and Altimeter Combination System (DUACS) and distributed by AVISO (http://www.aviso.oceanobs.com). This dataset merges along-track SSH measurements from all available satellite altimeter missions after October 1992 and has a 7-day temporal resolution and a $1 / 3^{\circ}$-longitude Mercator spatial resolution (Ducet et al. 2000). The data period analyzed in this study extends from October 1992 to December 2013 and the SSH anomalies are relative to the mean SSH field of this time period. From the SSH anomaly $h_{1}^{\prime}(x, y, t)$, the time-varying surface eddy velocity field $\mathbf{u}_{s}^{\prime}(x, y, t)$ is obtained by assuming geostrophic balance: $f \mathbf{k} \times \mathbf{u}_{s}^{\prime}=-g \nabla h_{1}^{\prime}$, where $f$ is the Coriolis parameter, $\mathbf{k}$ the unit vertical vector (positive upward), and $g$ the gravitational constant, respectively.

To evaluate the SSH changes induced by the external surface wind stress forcing, we utilize the European Centre for Medium-Range Weather Forecasts (ECMWF) Interim Re-Analysis (ERA-Interim) product (http://apps.ecmwf. int/datasets/data/interim_full_moda). Available from 1979 to the present, the ERA surface wind stress dataset has a monthly resolution and a $0.75^{\circ} \times 0.75^{\circ}$ spatial resolution (Dee et al. 2011).

\section{Model description}

To examine and quantify the regional sea level trend and variability in the North Pacific Ocean, we adopt in 
this study the two-layer primitive equation Hallberg Isopycnal Model (HIM; Hallberg 1997). In this twolayer configuration of HIM, the upper layer represents the upper ocean that is subject to direct surface wind stress forcing and the lower layer represents the abyssal ocean below the main thermocline. The momentum and continuity equations governing the two-layer ocean can be written as

$$
\begin{aligned}
\frac{\partial \mathbf{u}_{1}}{\partial t}+\mathbf{u}_{1} \cdot \nabla \mathbf{u}_{1}+f \mathbf{k} \times \mathbf{u}_{1}= & -g \nabla h_{1}+A_{2} \nabla^{2} \mathbf{u}_{1}-A_{4} \nabla^{4} \mathbf{u}_{1} \\
& +\frac{\boldsymbol{\tau}}{\rho_{1} H_{1}}-\mathbf{u}_{s}^{\prime} \cdot \nabla \mathbf{u}_{s}^{\prime}
\end{aligned}
$$$$
\frac{\partial\left(h_{1}-h_{2}\right)}{\partial t}+\nabla \cdot\left(H_{1} \mathbf{u}_{1}\right)=K_{2} \nabla^{2}\left(h_{1}-h_{2}\right),
$$$$
\frac{\partial \mathbf{u}_{2}}{\partial t}+\mathbf{u}_{2} \cdot \nabla \mathbf{u}_{2}+f \mathbf{k} \times \mathbf{u}_{2}=-g \nabla h_{1}-g^{\prime} \nabla h_{2}+A_{2} \nabla^{2} \mathbf{u}_{2}
$$$$
-A_{4} \nabla^{4} \mathbf{u}_{2}
$$$$
\frac{\partial h_{2}}{\partial t}+\nabla \cdot\left(H_{2} \mathbf{u}_{2}\right)=K_{2} \nabla^{2} h_{2}
$$

where $\mathbf{u}_{n}, H_{n}$, and $\rho_{n}$ are the $n$th layer velocity vector, thickness, and density, respectively, $h_{1}$ is the sea level anomaly, $h_{2}$ the layer interface anomaly (measured positive upward), $\tau$ the surface wind stress vector, $g^{\prime}=$ $\left(\rho_{2}-\rho_{1}\right) g / \rho_{2}$ the reduced gravity, $A_{2}\left(K_{2}\right)$ the horizontal Laplacian eddy viscosity (diffusivity), and $A_{4}$ the horizontal biharmonic eddy viscosity. The last term on the RHS of Eq. (1) represents the external eddy momentum flux forcing; its specification and rationale are given below.

As noted in the introduction, many previous modeling studies have addressed the sea level variability for the tropical Pacific Ocean (e.g., Timmermann et al. 2010; Merrifield and Maltrud 2011; Qiu and Chen 2012). For the present study, we set the model domain to be $0^{\circ}-$ $60^{\circ} \mathrm{N}$ and $120^{\circ} \mathrm{E}-75^{\circ} \mathrm{W}$ to focus on the extratropical North Pacific Ocean. The model has realistic coastline geometry determined by the $300-\mathrm{m}$ depth contours. The mean upper layer thickness of the model is set at $\bar{H}_{1}=500 \mathrm{~m}$ and the model's bottom topography follows the Smith and Sandwell (1997) dataset with a maximum ocean depth of $6000 \mathrm{~m}$. Notice that the bottom topography is allowed to pass through the layer interface in HIM. In the two-layer system, the speed of first-mode baroclinic Rossby waves is given by $c_{R}=$ $-\beta g^{\prime} \bar{H}_{1} \bar{H}_{2} / f^{2}\left(\bar{H}_{1}+\bar{H}_{2}\right)$, where $\beta=\partial f / \partial y$ [see Eq. (14) in Qiu 2002]. For our two-layer North Pacific model, we set $\rho_{1}=1025.0 \mathrm{~kg} \mathrm{~m}^{-3}$ and $\rho_{2}=1028.3 \mathrm{~kg} \mathrm{~m}^{-3}$ (or $g^{\prime}=$ $0.0315 \mathrm{~m} \mathrm{~s}^{-2}$ ), so that the $c_{R}$ values match those of the observations on the basin scale (Chelton et al. 2011). The horizontal eddy coefficients used in the model are $A_{2}=$ $K_{2}=500 \mathrm{~m}^{2} \mathrm{~s}^{-1}$ and $A_{4}=5 \times 10^{9} \mathrm{~m}^{4} \mathrm{~s}^{-1}$, respectively.

The model has a $1 / 6^{\circ} \times 1 / 6^{\circ}$ horizontal grid resolution. This grid resolution is chosen such that the model is neither too coarse to hinder the specification of eddy momentum fluxes nor too fine to result in a turbulent dynamical state. Given the horizontal eddy coefficients specified above, it does not resolve mesoscale eddies, although the advective effect by the large-scale circulation is retained in the model's governing equations. We retain this advective effect in order to better simulate the large-scale time-mean circulation in the North Pacific basin. To account for the effect of the mesoscale eddy forcings, we follow Greatbatch et al. (2010a,b) and include the eddy momentum flux forcing on the RHS of Eq. (1). Here, $\mathbf{u}_{s}^{\prime}$ is the surface anomalous geostrophic velocity evaluated from the AVISO product (see section 2 ). We choose to concentrate the eddy forcing in the upper layer because most of the mesoscale eddies in the North Pacific Ocean are generated by baroclinic/ barotropic instability of the time-mean Kuroshio Extension and STCC, whose horizontal and vertical shears are confined to above the main thermocline. To avoid estimation errors in $\mathbf{u}_{s}^{\prime}$ because of the small Coriolis parameter near the equator, the eddy momentum flux forcing is imposed on the upper layer of the two-layer model only north of $4^{\circ} \mathrm{N}$. Notice that Greatbatch et al.'s (2010a,b) studies have focused on the mean sea level changes in the Gulf Stream and Kuroshio Extension regions induced by the time-mean eddy forcing $-\overline{\mathbf{u}_{s}^{\prime} \cdot \nabla \mathbf{u}_{s}^{\prime}}$. It is the timevarying sea level fluctuations induced by the time-varying eddy forcing that constitute the focus of our present investigation. Within the framework of our chosen approach, the $-\mathbf{u}_{s}^{\prime} \cdot \nabla \mathbf{u}_{s}^{\prime}$ term can be regarded as a diagnostically prescribed external forcing, similar to that of the surface wind stress forcing. Along the model boundaries, a free-slip condition is used along the open southern boundary and a no-slip condition is imposed along the other coastal and marginal sea boundaries.

Three model runs are performed in the present study. In the "wind forcing" run, the model ocean is initialized at rest and forced by the monthly ERA surface wind stresses from 1979 to 2013. This model run is in line with the previous numerical model studies focusing on the tropical wind-driven sea level variability. In the "eddy forcing" run, the model is spun up by the climatological $-\mathbf{u}_{s}^{\prime} \cdot \nabla \mathbf{u}_{s}^{\prime}$ forcing from January 1979 to September 1992; here, the climatological $-\mathbf{u}_{s}^{\prime} \cdot \nabla \mathbf{u}_{s}^{\prime}$ values are constructed by averaging the observed monthly $-\mathbf{u}_{s}^{\prime} \cdot \nabla \mathbf{u}_{s}^{\prime}$ values from 1992 to 2013. The model is then forced by the 
(a) ECMWF Wind Forcing: $\eta$ Mean

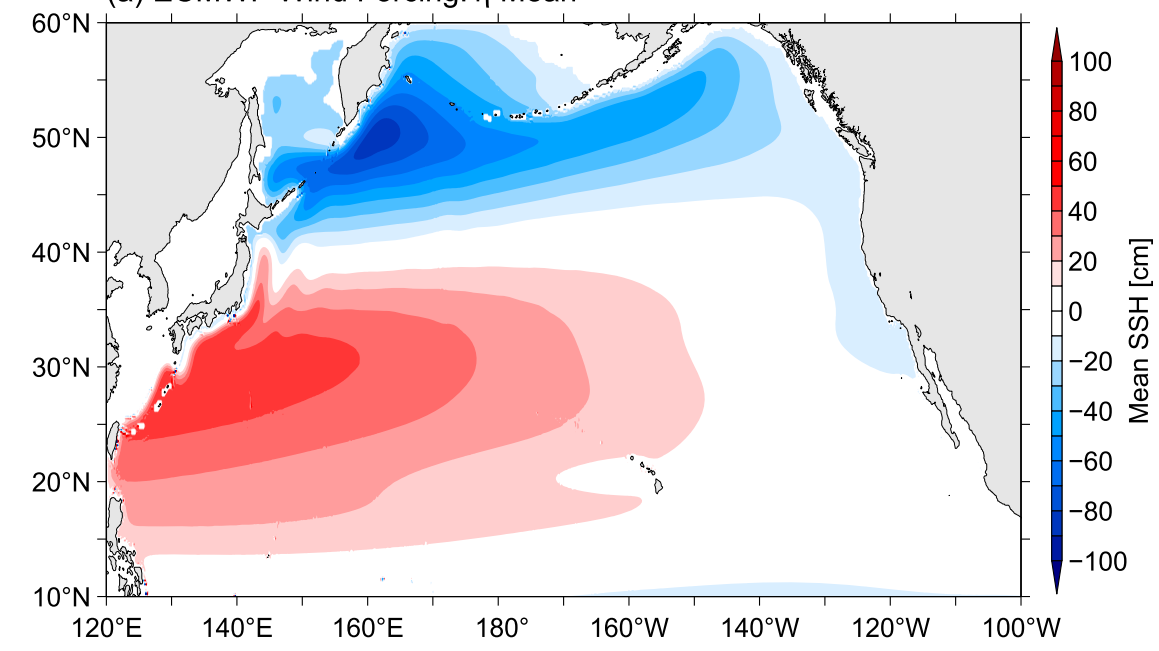

(b) $\eta$ Trend

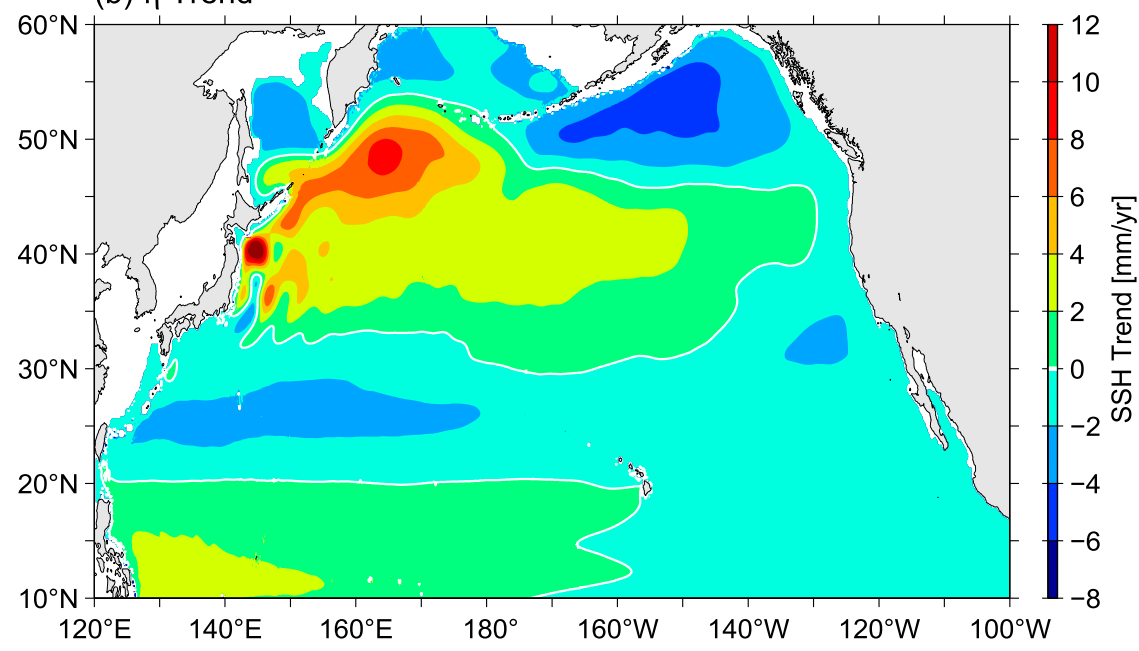

FIG. 4. (a) Mean SSH and (b) linear sea level trend from the HIM simulation forced by the surface wind stresses. Both mean and trend values are evaluated for the period of October 1992-December 2013.

observed, weekly $-\mathbf{u}_{s}^{\prime} \cdot \nabla \mathbf{u}_{s}^{\prime}$ values from October 1992 to December 2013. Both the wind and eddy forcings are imposed in the "full forcing" model run. In the following analyses, we will focus on 1992-2013, the two decades when the observed sea level signals are available for comparison (cf. Fig. 2). All trend values presented in this study are specific to the period from October 1992 to December 2013.

\section{Analyses of model output}

a. The wind-forcing run

Figure 4a shows the mean SSH field during 1992-2013 from the wind forcing-run. This model run simulates well the large-scale subtropical and subarctic gyre circulations in the North Pacific. The run is also successful in capturing some of the subgyre-scale circulation features, such as the S-shaped SSH perturbation west of the Hawaiian Islands seen in the observed mean SSH field (Fig. 2a). The model run, however, misrepresents the important western boundary current features. As is commonly found in the non-eddy-resolving simulations (e.g., Hurlburt et al. 1996; Nakano and Ishikawa 2010), the modeled Kuroshio in Fig. 4a overshoots poleward east of Japan and the time-mean Kuroshio Extension penetrates too diffusively into the interior Pacific Ocean. As will be demonstrated below, these model deficiencies are removed once the observed eddy forcing is taken into account.

Figure $4 \mathrm{~b}$ shows the modeled linear sea level trend from 1992 to 2013 in the wind-forcing run. Compared to the observed linear trend map shown in Fig. 2b, one can 
easily detect an agreement in broad-scale spatial patterns. Specifically, positive trends appear both in the western tropical basin (i.e., $<20^{\circ} \mathrm{N}$ ), the central midlatitude basin $\left(30^{\circ}-40^{\circ} \mathrm{N}, 160^{\circ} \mathrm{E}-140^{\circ} \mathrm{W}\right)$, and the western aubarctic gyre. Similarly, broad-scale negative trends can be seen both in the eastern tropical basin, the western and eastern subtropical regions of $20^{\circ}-30^{\circ} \mathrm{N}$, and the Alaska gyre. In terms of the trend amplitude, the model is more successful in the subtropical regions, but tends to underestimate the trends in the tropical regions and overestimate in the subarctic regions.

Notice that the under- and overestimations of the trend amplitude are due to the limitation of the twolayer model representation. For the present study, the upper-layer thickness and the reduced-gravity constant of the model have been selected to best represent the subtropical midlatitude North Pacific Ocean. If one were to focus on the wind-forced sea level changes in the tropical region, a larger reduced gravity constant (i.e., a more stratified two-layer model ocean) would be preferred, and for the subarctic region, a smaller $g^{\prime}$ would be more representative. For the reason of this $g^{\prime}$ dependence, readers are referred to the appendix, where we expound the physical processes governing the large-scale, wind-forced, sea level changes in a twolayer ocean.

Despite the agreement in broad-scale patterns, noticeable differences between Figs. $2 \mathrm{~b}$ and $4 \mathrm{~b}$ become apparent when one zooms to the trend signals on the subgyre scales of $O(500-1000) \mathrm{km}$. For example, in the western subtropical band of $20^{\circ}-30^{\circ} \mathrm{N}$, Fig. $2 \mathrm{~b}$ reveals that the broad-scale negative trend is sandwiched by a weak-positive trend band centered along $25^{\circ} \mathrm{N}$. Such a band is nonexistent in Fig. 4b. In the Kuroshio Extension and mixed water regions east of Japan $\left(33^{\circ}-\right.$ $40^{\circ} \mathrm{N}, 140^{\circ}-160^{\circ} \mathrm{E}$ ), instead of an overall positive trend found in the model, the observed trend exhibits a distinctive dipolar pattern with the sea level increasing and decreasing south and north of $36^{\circ} \mathrm{N}$, respectively.

In summary, the surface wind stress forcing is responsible for many of the broad-scale sea level trends observed in the North Pacific Ocean over the past two decades. However, the subgyre-scale sea level trends that appear predominantly in the western subtropical basin cannot be explained by wind forcing alone.

\section{b. The eddy-forcing run}

Figure 5a shows the mean SSH field from the model run forced by the eddy momentum fluxes inferred diagnostically from the AVISO SSH data. By and large, the time-mean circulation in this case can be characterized by two pairs of counterrotating recirculations in the western basin. The first pair has its axis along approximately $34^{\circ} \mathrm{N}$, following the path of the eastward-flowing Kuroshio Extension jet. This pair of recirculations is known as the Kuroshio Extension's southern and northern recirculation gyres and their existence has been confirmed observationally by available profiling float and moored current meter measurements (Qiu et al. 2008; Jayne et al. 2009; Waterman et al. 2011). Dynamically, the importance of the eddy flux convergence forcing in generating the Kuroshio Extension recirculation gyres has been emphasized by many modeling studies (e.g., Greatbatch et al. 2010a; Qiu and Chen 2010a; Nakano and Ishikawa 2010; Taguchi et al. 2010).

In regard to the sea level trend in the Kuroshio Extension region, Fig. $5 \mathrm{~b}$ reveals that it mirrors well the mean sea level pattern shown in Fig. 5a: the time-varying eddy forcing causes an increased (decreased) regional sea level in the southern (northern) recirculation gyre. Geostrophically, this implies an enhancement of both the Kuroshio Extension recirculation gyres during the 1992-2013 period.

The second pair of the eddy-driven recirculation gyres has its center along $\sim 20^{\circ} \mathrm{N}$ and its generation is associated with the unstable STCC in the western subtropical Pacific Ocean (Qiu 1999; Kobashi and Kawamura 2002). As the rms eddy variability of the STCC is smaller in amplitude than that of the Kuroshio Extension (recall Fig. 3a), the magnitude and meridional scale of the STCC recirculation gyres are smaller in comparison with the Kuroshio Extension recirculation gyres. Notice that unlike the Kuroshio Extension recirculation gyres, little attention has been paid heretofore to the recirculation gyre accompanying the STCC.

In terms of the sea level trend, Fig. 5b shows that its spatial patterns in the STCC region have opposite signs to those of the eddy-forced, time-mean sea level patterns. Specifically, the sea level trend is positive north of $22^{\circ} \mathrm{N}$ and negative south of $22^{\circ} \mathrm{N}$. The reason for these linear trend patterns having opposite signs to the timemean STCC recirculation gyre sea level patterns will be discussed in section 5 .

\section{c. The combined wind-and eddy-forcing run}

Figure 6 a shows the mean sea level field when both the wind stress and eddy momentum flux forcing are applied. Compared to the mean sea level pattern forced by the wind stress only (Fig. 4a), it is clear that adding the eddy forcing causes the Kuroshio Extension to separate from the Japan coast at approximately $35^{\circ} \mathrm{N}$ and to maintain a meridionally confined $\mathrm{SSH}$ gradient (i.e., a coherent eastward jet) that extends into the interior Pacific Ocean. Both of these features are readily seen in the observed mean SSH map of Fig. 2a. Under the 
(a) Eddy Forcing: $\eta$ Mean

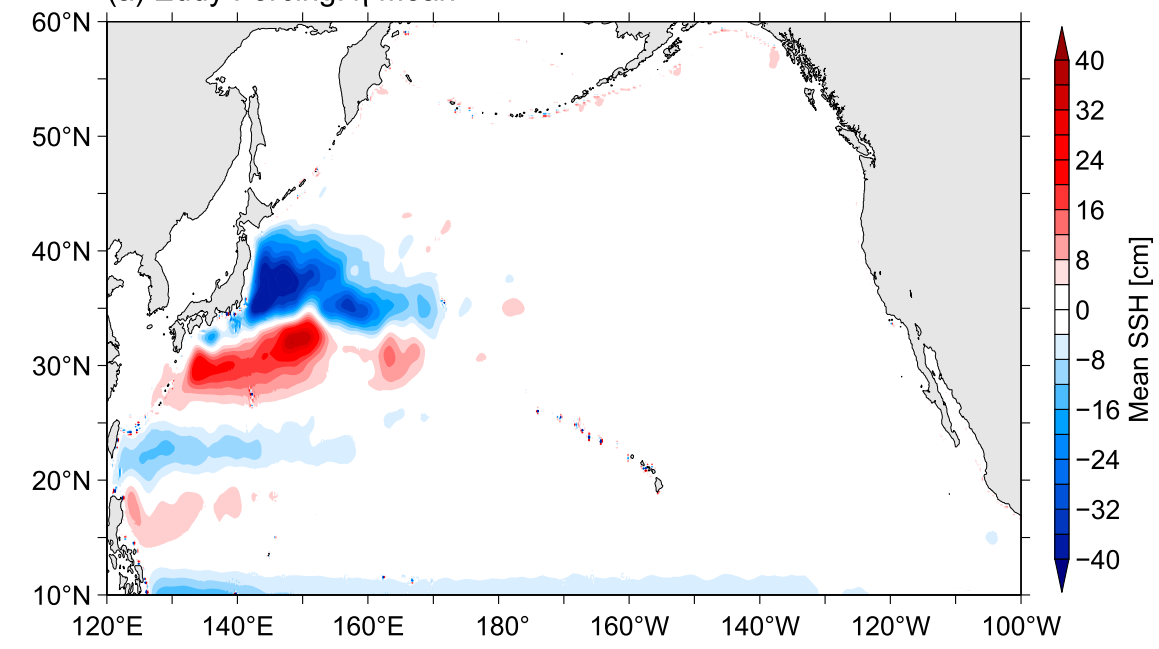

(b) $\eta$ Trend

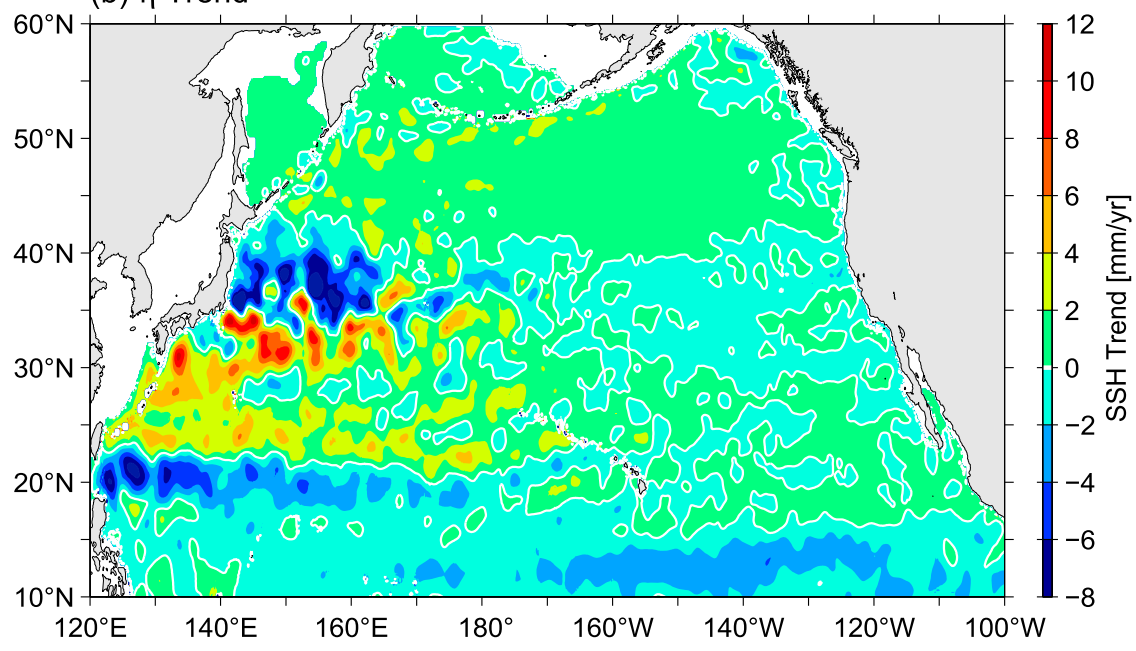

FIG. 5. (a) Mean SSH and (b) linear sea level trend from the HIM simulation forced by the eddy momentum fluxes. Both mean and trend values are evaluated for the period of October 1992-December 2013.

combined wind and eddy forcing, the dynamical state of the Kuroshio is similarly improved south of Japan: instead of a Munk-type western boundary current with a diffusive return flow shown in Fig. 4a, Fig. 6a reveals that the timemean Kuroshio has a quasi-stationary meandering path and is accompanied by an intense offshore southern recirculation gyre. These features represent well the observed dynamical state of the Kuroshio south of Japan (Fig. 2a).

Figure 6b shows the linear sea level trend in 19922013 from the combined wind- and eddy-forcing run. Although its pattern appears "spottier" than that in the observed trend map of Fig. 2b, the modeled sea level trend has an overall spatial distribution consistent with the observations. For example, the sea level trend is largely negative north of the Kuroshio Extension from $140^{\circ}$ to $165^{\circ} \mathrm{E}$ and it switches to positive values in the narrow southern band of $32^{\circ}-36^{\circ} \mathrm{N}$. Farther to the south in the broad subtropical region of $19^{\circ}-32^{\circ} \mathrm{N}$ and west of the date line, the modeled sea level trend is mostly negative and is interspersed by a weak positive trend band along approximately $24^{\circ} \mathrm{N}$ as in the observations.

For a more quantitative comparison, we plot in Fig. 7 the modeled and observed interannual sea level time series in the negative trend band north of the Kuroshio Extension (Fig. 7a), the positive trend band south of the Kuroshio Extension (Fig. 7b), the positive trend band north of the STCC (Fig. 7c), and the negative trend band south of the STCC region (Fig. 7d). With the exception 
(a) Wind and Eddy Forcing: $\eta$ Mean

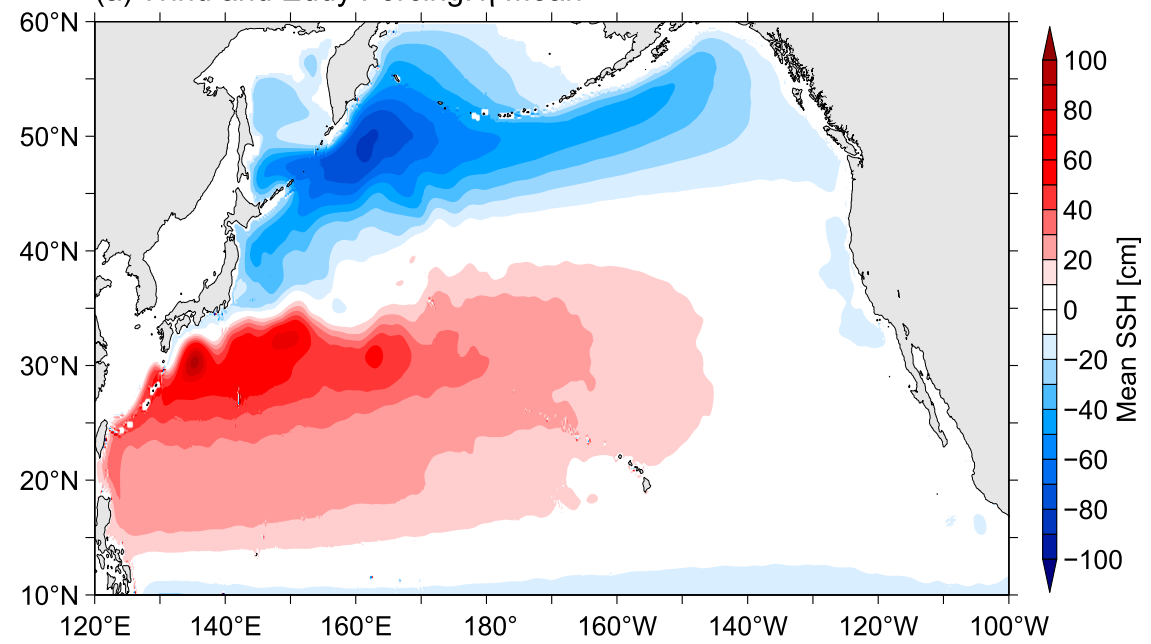

(b) $\eta$ Trend

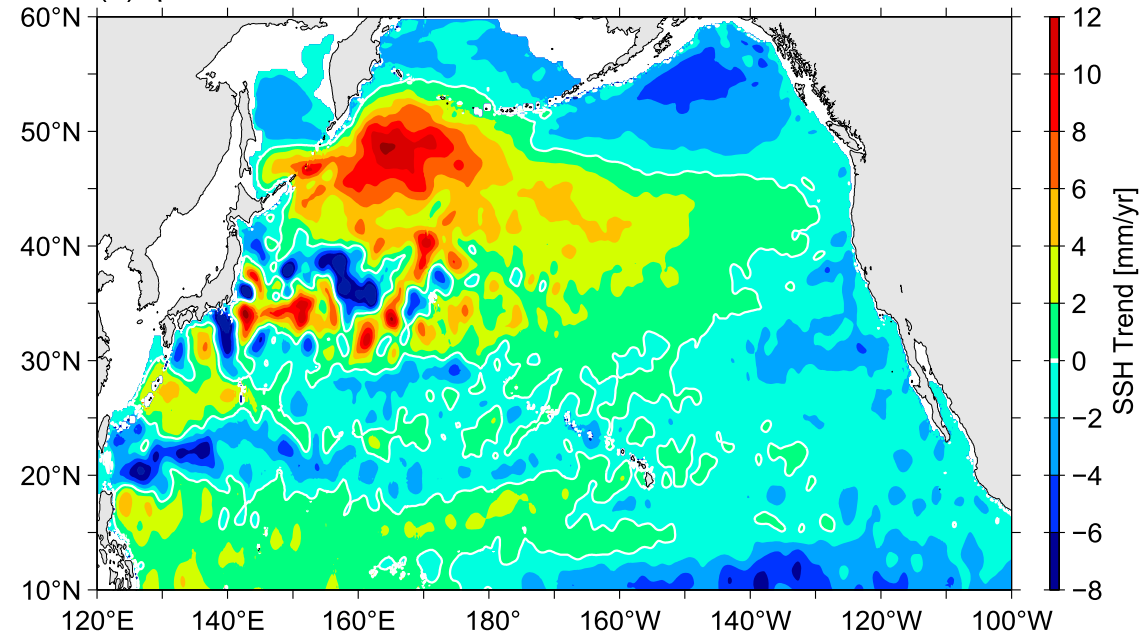

FIG. 6. (a) Mean SSH and (b) linear sea level trend from the HIM simulation forced by combined surface wind and eddy momentum stresses. Both mean and trend values are evaluated for the period of October 1992-December 2013.

of the band north of the STCC (Fig. 7c), the modeled sea level trends (blue dashed lines) all match favorably with the observed trends (red dashed lines). In the band north of the STCC, the modeled sea level trend exceeds the observed trend. It is worth remembering that the trends shown in Fig. 7 are relative to the global mean value $3.2 \mathrm{~mm} \mathrm{yr}^{-1}$. In other words, with the observed $-3.8 \mathrm{~mm} \mathrm{yr}^{-1}$ trend shown in Fig. $7 \mathrm{a}$, the net decreasing sea level trend in the northern Kuroshio Extension region has been merely $-0.6 \mathrm{~mm} \mathrm{yr}^{-1}$ over the past two decades. In contrast, the observed $4.1 \mathrm{~mm} \mathrm{yr}^{-1}$ trend shown in Fig. $7 b$ indicates that the regional net sea level rise south of the Kuroshio Extension exceeds twice the global mean trend. This point regarding the relativity to the global mean sea level is valid for the trends north and south of the STCC as well.
For the region south of the Kuroshio Extension, it is interesting to note that the combined wind- and eddyforcing run is capable of reproducing the decadal sea level modulations observed by the satellite measurements. In comparison, the combined forcing run is less successful in simulating the interannual sea level changes in the region north of the Kuroshio Extension (Fig. 7a). This difference in capability of simulating the sea level changes on the two sides of the Kuroshio Extension was also noted in our previous study (see Fig. 9 in Qiu 2003). The northern Kuroshio Extension region is characterized by outcropping of ventilated isopycnal surfaces and is subject to intense air-sea heat flux forcing (Qiu et al. 2004). A better simulation of the interannual sea level changes in this region will likely require diabatic surface forcing and a dynamical model 

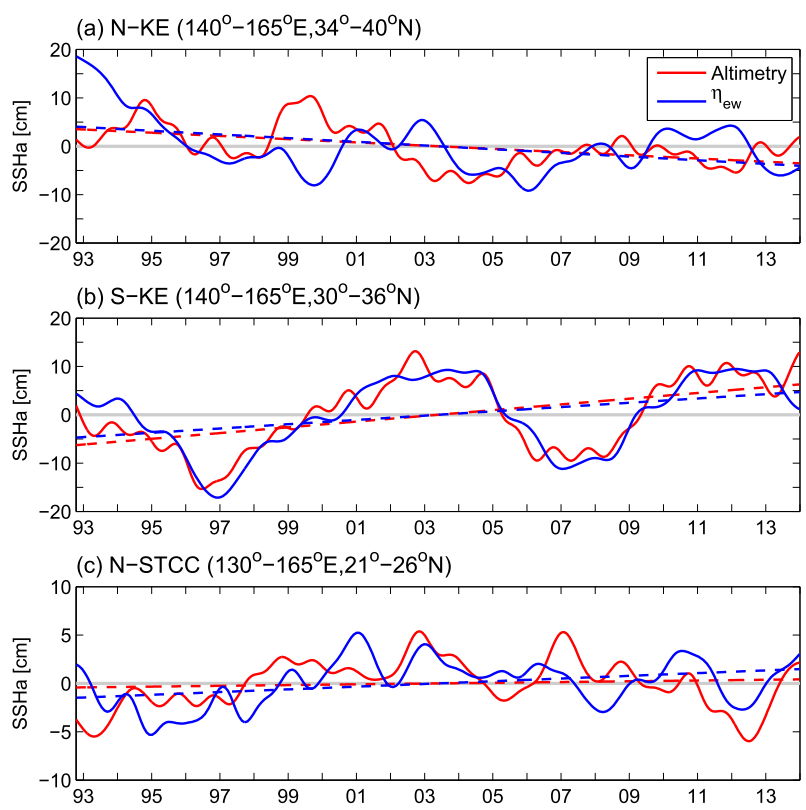

(d) S-STCC $\left(130^{\circ}-165^{\circ} \mathrm{E}, 19^{\circ}-24^{\circ} \mathrm{N}\right)$

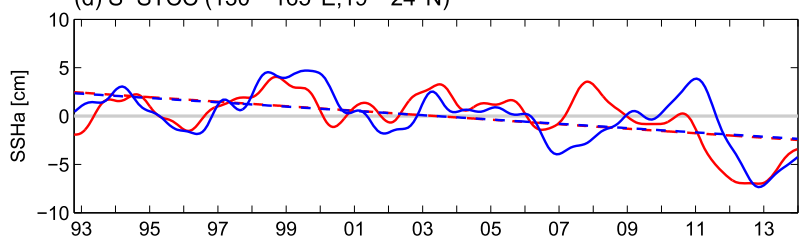

FIG. 7. Time series of yearly-averaged sea level anomalies in the regions (a) $34^{\circ}-40^{\circ} \mathrm{N}, 140^{\circ}-165^{\circ} \mathrm{E}$ with negative trend; (b) $30^{\circ}-36^{\circ} \mathrm{N}$, $140^{\circ}-165^{\circ} \mathrm{E}$ with positive trend; (c) $21^{\circ}-26^{\circ} \mathrm{N}, 130^{\circ}-165^{\circ} \mathrm{E}$ with positive trend; and (d) $19^{\circ}-24^{\circ} \mathrm{N}, 130^{\circ}-165^{\circ} \mathrm{E}$ with negative trend. Red lines show the AVISO observations and blue lines, the results of combined wind- and eddy-forcing run. Straight dashed lines denote the linear trends during October 1992-December 2013.

more sophisticated than the two-layer HIM. This topic will be pursued in our future studies.

\section{Discussion and summary}

\section{a. Eddy-forced variability in the presence of wind-driven circulation}

In the preceding section, we quantified the regional sea level trend signals due to the wind stress, the eddy momentum flux, and their combined forcing, respectively. It is worth emphasizing that although the wind stress and eddy momentum flux appear as additive forcing in Eq. (1), the results of the combined wind- and eddy-forcing run shown in Fig. 6 are not simply the sum of the wind and eddy forcing runs shown in Figs. 4 and 5. This is so because as the wind forcing deforms the upperlayer thickness $H_{1}$, it modifies the equivalent layer depth $H_{e}=H_{1} H_{2} /\left(H_{1}+H_{2}\right)$ and affects how the barotropic and baroclinic sea levels adjust to the wind and eddy forcings (see the appendix for details). Since the eddy variability would not have existed in the absence of wind forcing, ${ }^{1}$ a different way to quantify the eddy-induced mean sea level and trend is to subtract the results of the combined wind- and eddy-forcing run from those of the wind forcing only run. Figure 8 shows the mean sea level and trend maps thus constructed. For the sea level trend, while Fig. 8 b exhibits a spatial pattern similar to that of Fig. 5b, subtle differences also exist: for example, the zero trend contour running between Taiwan and Hawaii in Fig. $8 \mathrm{~b}$ is located along a more northerly latitude, about $23^{\circ} \mathrm{N}$, than in Fig. $5 \mathrm{~b}\left(\sim 22^{\circ} \mathrm{N}\right)$. Overall, the zonally banded trend structures in $18^{\circ}-40^{\circ} \mathrm{N}$ of the northwestern Pacific in the combined wind- and eddy-forcing run (Fig. 6b) match better with those shown in Fig. 8b than in Fig. 5b.

To quantify the relative importance of wind versus eddy forcing, we divide the modeled sea level signals shown in Fig. 7 into those forced by the wind stresses and by the eddy fluxes (defined by the difference between the combined wind- and eddy-forcing and the windforcing runs). As indicated in Fig. 9, the wind and eddy forcings contribute differently in different latitude bands. North of the Kuroshio Extension, the modeled negative sea level trend is exclusively determined by the eddy forcing. In fact, Fig. 9a indicates that the wind forcing, if acting alone, would have produced a positive sea level trend in this band. South of the Kuroshio Extension, on the other hand, the eddy forcing contributes predominantly to the regional positive trend and decadal sea level modulations. Similar to Fig. 9a, along the band north of the STCC, the wind and eddy forcings generate oppositely signed sea level trends and the resultant positive trend is dictated by the eddy forcing (Fig. 9c). In the band south of the STCC shown in Fig. 9d, on the other hand, the wind and eddy forcings contribute constructively to the regional negative sea level trend. Their relative contributions to the total negative trend are $34 \%$ and $66 \%$, respectively.

\section{b. Processes responsible for wind-forced regional sea level trends}

As shown in Fig. 4b, the regional sea level trends forced by the wind stresses have gyre-scale spatial patterns and are positive in the western tropical and subarctic gyres and negative in the subtropical and eastern tropical and subarctic gyres, respectively. The dominant large-scale wind stress variability over the North Pacific Ocean is that associated with the Pacific decadal

\footnotetext{
${ }^{1}$ The eddy variability shown in Fig. 3 is due to instability of the time-mean Kuroshio Extension and STCC, both of which are circulation features driven by large-scale wind forcing.
} 
(a) Mean of $\eta_{e w}-\eta_{w}$

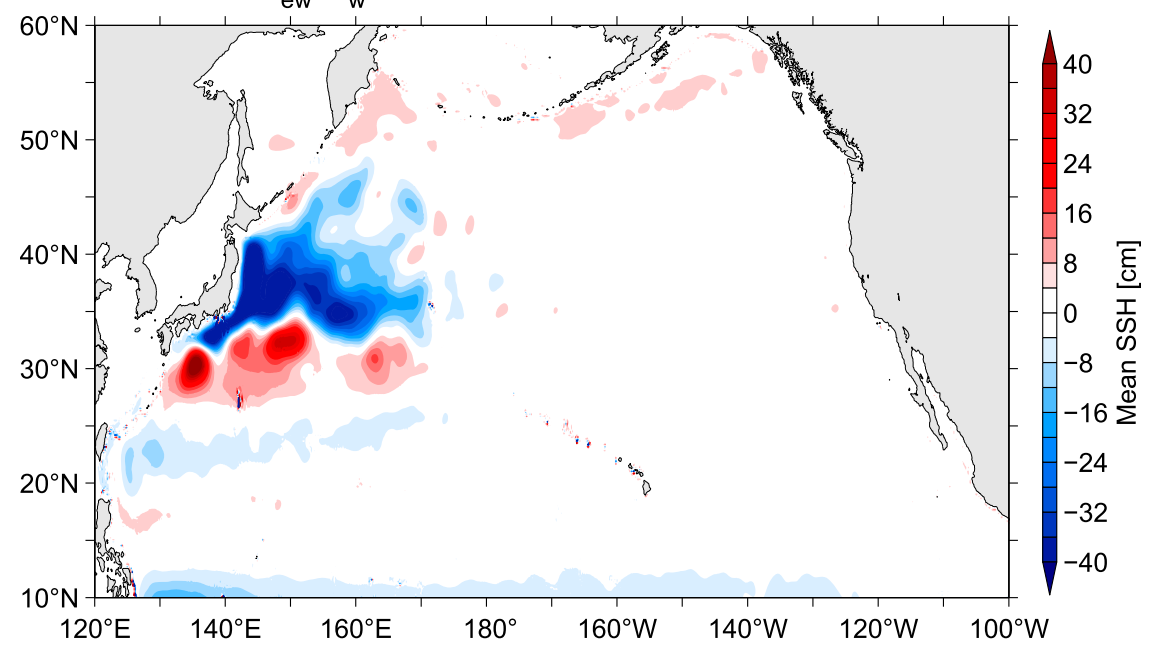

(b) Trend of $\eta_{e w}-\eta_{w}$

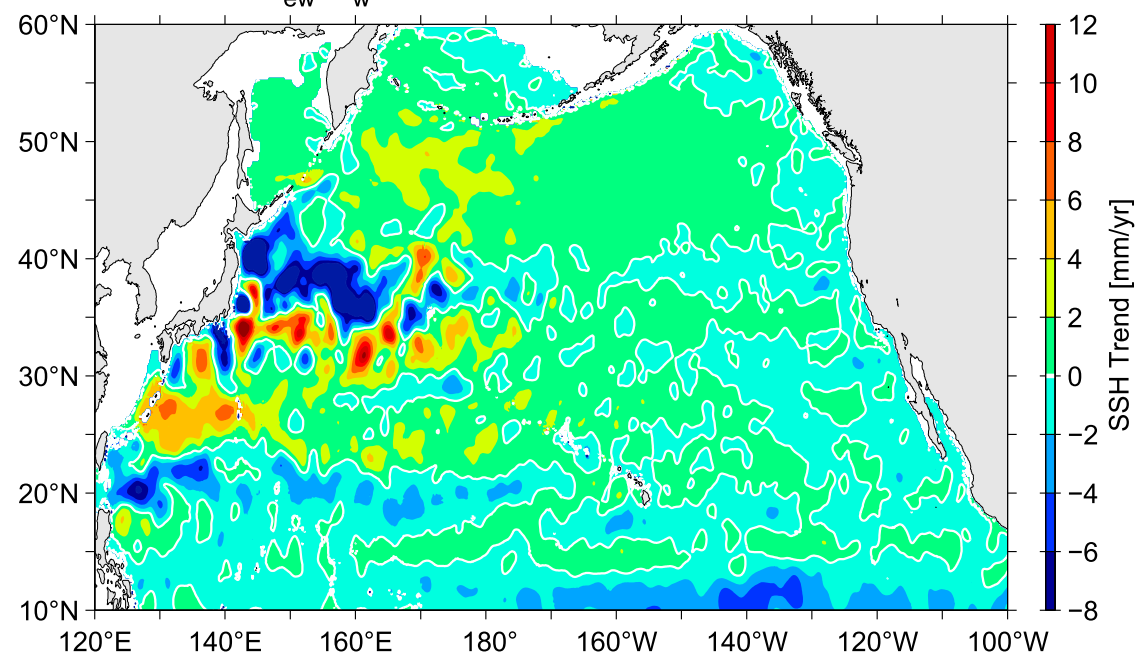

FIG. 8. (a) Mean SSH and (b) linear sea level trend based on the difference between the models with combined wind and eddy forcing and that with wind forcing alone. Both mean and trend values are evaluated for the period October 1992-December 2013.

oscillation (PDO) defined by the leading principal component of the North Pacific monthly sea surface temperature anomalies poleward of $20^{\circ} \mathrm{N}$ (Mantua et al. 1997). In Fig. 10a, we plot the PDO index time series of the past two decades and there exists a clear transition from a positive to negative PDO phase. Figure 10b shows the spatial wind stress vector and curl pattern regressed to the PDO index during the 1993-2013 period of our interest. Notice that the spatial pattern of wind stress curl is by and large consistent with the wind-forced regional sea level trend patterns shown in Fig. 4b. For example, decreased positive wind stress curl in the western tropical and the midlatitude band of $35^{\circ}-53^{\circ} \mathrm{N}$ is responsible for the sea level rise in these regions, and decreased negative wind stress curl in the western subtropical band of $19^{\circ}-35^{\circ} \mathrm{N}$ and in the Alaska gyre is responsible for the sea level drop in these regions.

Rather than a one-to-one local correspondence between the wind stress curl and regional sea level signals, theoretical analyses presented in the appendix indicate that the wind stress curl-induced sea level variability tends to migrate westward resulting from the planetary $\beta$ effect. Such a westward shift between the wind stress curl pattern and the wind-forced regional sea level trend pattern is easily discernible by comparing Figs. $10 \mathrm{~b}$ and $4 \mathrm{~b}$. The importance of westward propagation in determining the wind-forced sea level changes has been emphasized by many existing studies for the tropical and extratropical North Pacific Ocean (e.g., Kessler 1990; Qiu and Chen 2005, 2010b; Taguchi et al. 2007; Ceballos 

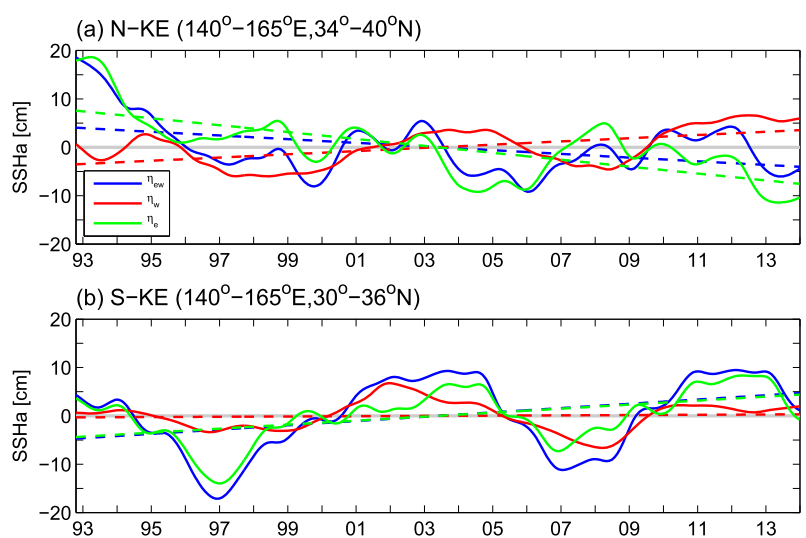

(c) N-STCC $\left(130^{\circ}-165^{\circ} \mathrm{E}, 21^{\circ}-26^{\circ} \mathrm{N}\right)$

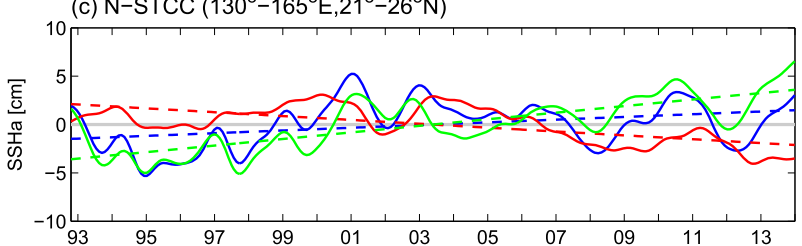

(d) S-STCC $\left(130^{\circ}-165^{\circ} \mathrm{E}, 19^{\circ}-24^{\circ} \mathrm{N}\right)$

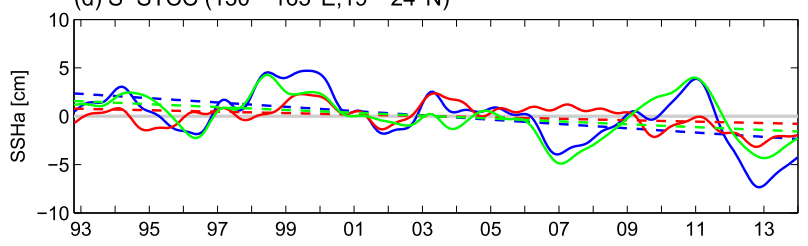

FIG. 9. Time series of yearly-averaged sea level anomalies in the regions (a) $34^{\circ}-40^{\circ} \mathrm{N}, 140^{\circ}-165^{\circ} \mathrm{E}$ with negative trend; (b) $30^{\circ}-$ $36^{\circ} \mathrm{N}, 140^{\circ}-165^{\circ} \mathrm{E}$ with positive trend; (c) $21^{\circ}-26^{\circ} \mathrm{N}, 130^{\circ}-165^{\circ} \mathrm{E}$ with positive trend; and (d) $19^{\circ}-24^{\circ} \mathrm{N}, 130^{\circ}-165^{\circ} \mathrm{E}$ with negative trend. Blue lines show the results of combined wind- and eddyforcing run (same as in Fig. 7). Red lines show the wind-forcing run results and green lines show the difference between the combined and wind forcing runs. Straight dashed lines denote the linear trends during October 1992-December 2013.

et al. 2009). As such, no further quantification is pursued further in this study.

\section{c. Processes responsible for eddy-forced regional sea level trends}

In comparison with the wind-forced sea level trends, large-amplitude eddy-forced sea level trends are confined to the Kuroshio Extension and STCC regions where intense mesoscale eddy signals are present (recall Fig. 3a). The noticeable features of the eddy-driven sea level trends are the dipolar negative (positive) trends north (south) of the Kuroshio Extension versus the dipolar positive (negative) trends north (south) of the STCC (Fig. 8b). The cause for the dipolar trends across the Kuroshio Extension is due to the increasing eddy kinetic energy (EKE) trend in the Kuroshio Extension region of $150^{\circ}-170^{\circ} \mathrm{E}$ as depicted in Fig. 11a (see also Fig. 3b). Many theoretical and modeling studies in the past have indicated that an unstable zonal jet, such as the Kuroshio Extension, can drive a low sea level cyclonic recirculation gyre northwest of the zonal jet and a high sea level anticyclonic recirculation gyre southwest of the zonal jet (e.g., Jayne et al. 1996; Qiu et al. 2008; Taguchi et al. 2010; Waterman and Jayne 2011). As the recirculation gyre strength is proportional to the intensity of the eddy forcing, the increased EKE level in the downstream Kuroshio Extension region should lead to intensification of the northern and southern recirculation gyres, or the regional sea level decrease and increase north and south of the Kuroshio Extension jet, respectively. These eddy-forced decreasing/increasing trends are clearly reflected by the green dashed lines in Figs. 9a and 9b.

Along the eastward-flowing STCC band of $20^{\circ}-24^{\circ} \mathrm{N}$ in the western subtropical North Pacific, Fig. 11b reveals that there exists a decreasing trend in the EKE level (see also Fig. 3b). Following the same theoretical argument, the eddy-forced regional sea level trend should increase and decrease northwest and southwest of the STCC, respectively. These eddy-forced sea level trends are delineated in Figs. 9c and 9d by the green dashed lines.

Notice that the EKE trend signals detected in the Kuroshio Extension and STCC regions are induced by the PDO wind stress forcing. In the STCC region, several recent analyses indicate that the regional EKE signals are positively correlated to the PDO-related surface wind and heat forcing (Yoshida et al. 2011; Qiu and Chen 2013; see also the red line in Fig. 11c). Specifically, when the PDO index is in its positive phase (Fig. 10b), the enhanced midlatitude westerlies along $28^{\circ}-35^{\circ} \mathrm{N}$ and the enhanced tropical easterlies along $15^{\circ}-23^{\circ} \mathrm{N}$ intensify the meridional Ekman temperature flux convergence and strengthen the eastward-flowing STCC in the western North Pacific. By increasing the vertical shear of the STCC-NEC system, baroclinic instability along the STCC is enhanced, resulting in a higher level of regional EKE. The reverse is true when the PDO switches to its negative phase.

Along the Kuroshio Extension latitude band, on the other hand, the wind stress curl forcing in the positive PDO phase (cf. Fig. 10b) tends to induce negative sea level anomalies in the eastern North Pacific basin because of surface Ekman flux divergence. After these wind-forced negative sea level anomalies propagate westward into the Kuroshio Extension after a delay of about 3 or more years, they work to shift the Kuroshio Extension jet southward, causing the EKE level to increase in the upstream Kuroshio Extension region of $140^{\circ}-153^{\circ} \mathrm{E}$ and to decrease in the downstream region of $153^{\circ}-170^{\circ} \mathrm{E}$ (Qiu and Chen 2005, 2011, and references therein). During the negative PDO phase, the opposite processes are at work and the EKE level in the downstream Kuroshio Extension tends to increase after 
(a) PDO Index

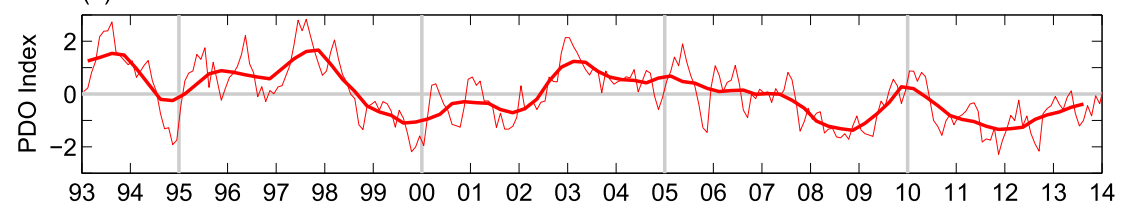

(b) ECMWF Wind Regression to Normalized PDO: 1993-2013

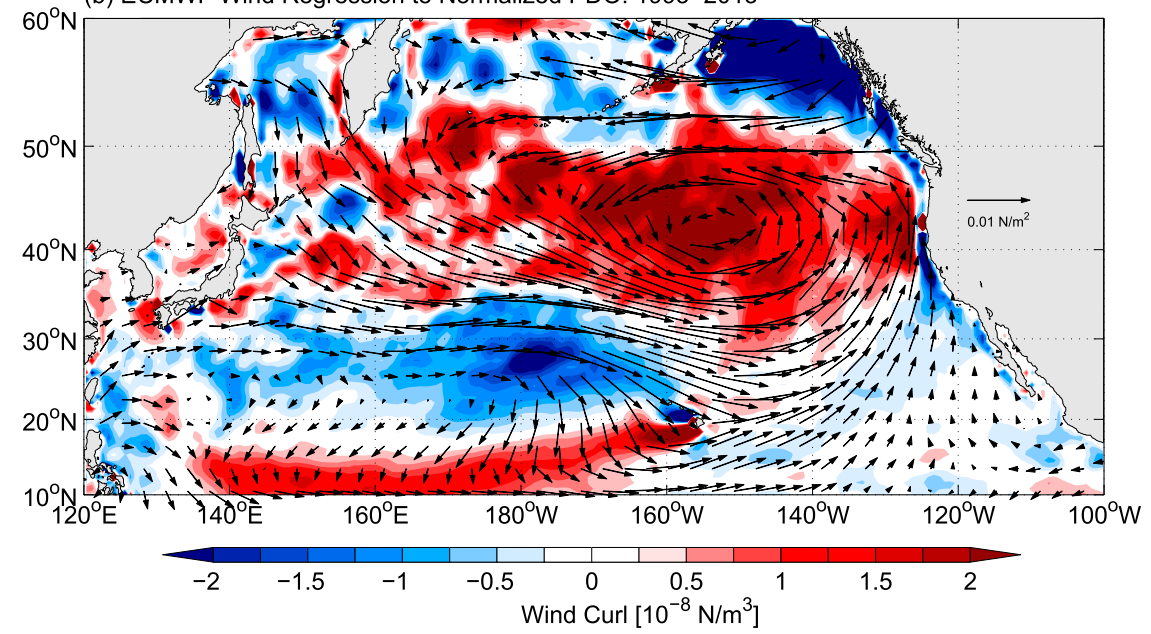

FIG. 10. (a) Time series of PDO index from http://jisao.washington.edu/pdo/PDO.latest. Thin line denotes the original monthly time series and thick line, the yearly-average time series. (b) Surface wind stress vectors and wind curl (in color) regressed to the annually averaged PDO time series.

a delay of 3-4 years (Fig. 11c). At present, the exact mechanism for the downstream EKE in the Kuroshio Extension region to decrease (increase) once the PDOinduced negative (positive) sea level anomalies reach the Kuroshio Extension jet, remains unclear. One possibility is that the zonal Kuroshio Extension jet experiences large latitudinal migration following the PDO wind forcing and that its downstream EKE level is controlled by the interaction between the migrating Kuroshio Extension jet and the underlying, meridionally aligned, bathymetry, such as the Shatsky Rise along approximately $159^{\circ} \mathrm{E}$ and the Emperor Seamounts along approximately $175^{\circ} \mathrm{E}$. For a better understanding and prediction of the regional sea level variability surrounding the Kuroshio Extension region, future studies are needed to clarify the processes that determine the EKE levels in the up- and downstream Kuroshio Extension regions.

Throughout this subsection, we have emphasized the PDO-related wind stress forcing as represented in Fig. 10. For the decadal Kuroshio Extension variability, several recent studies have pointed to the importance of the wind stress forcing associated with the North Pacific Gyre Oscillation (NPGO) index, defined by the second principal component of the monthly sea level anomalies in the northeastern Pacific region $25^{\circ}-62^{\circ} \mathrm{N}, 180^{\circ}-110^{\circ} \mathrm{W}$ (e.g., Ceballos et al. 2009; Pierini 2014). While the PDO and NPGO indices are largely independent for the long period of 1950-2004 (Di Lorenzo et al. 2008), they are correlated during the last two decades of interest to this study. For example, Fig. 12a shows the negative NPGO index time series from 1993 to 2013. Compared to the PDO index depicted in Fig. 10a, the two indices are correlated with a coefficient $r=-0.41$ between the original monthly time series and $r=-0.65$ between their annually averaged time series (the thick lines in Figs. 10a and 12a). Given this high correlation, it is not surprising that the wind stress curl pattern regressed to the NPGO index (Fig. 12b) bears a good resemblance to that of Fig. 10b. In other words, the above discussions in connection to the PDO forcing can be effectively replaced by the negative NPGO forcing as far as the windand eddy-forced regional sea level changes in the last two decades are concerned.

Acknowledgments. Detailed and constructive comments made by the three reviewers helped improve an early version of the manuscript. The ERA-Interim reanalysis surface wind stress data are provided by the European Centre for Medium-Range Weather Forecast, and the merged satellite altimeter data by the CLS Space Oceanography Division as part of the Environment and Climate EU ENACT project. BQ and SC acknowledge the support of NSF OCE-0926594. LW is supported through the National Global Change Major 
(a) EKE in Downstream KE $\left(33^{\circ}-37^{\circ} \mathrm{N}, 150^{\circ}-170^{\circ} \mathrm{E}\right)$

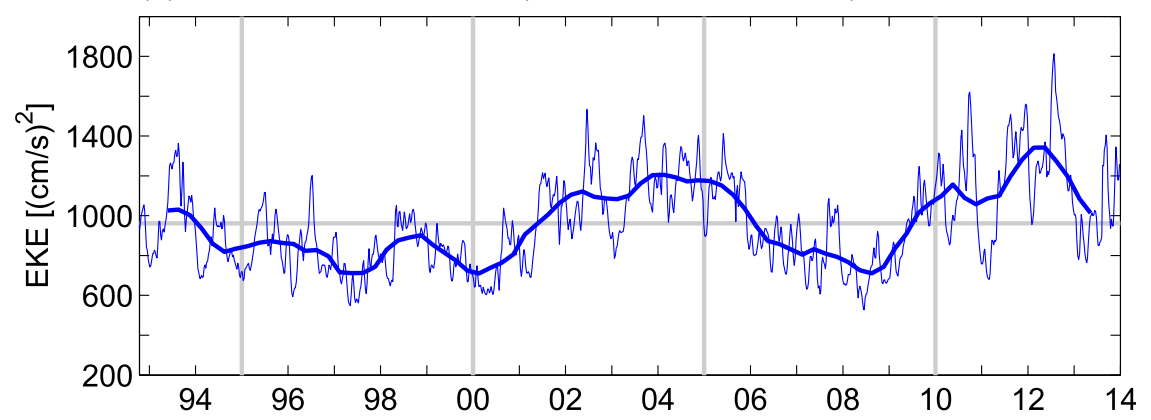

(b) EKE in STCC $\left(20^{\circ}-24^{\circ} \mathrm{N}, 140^{\circ} \mathrm{E}-170^{\circ} \mathrm{W}\right)$

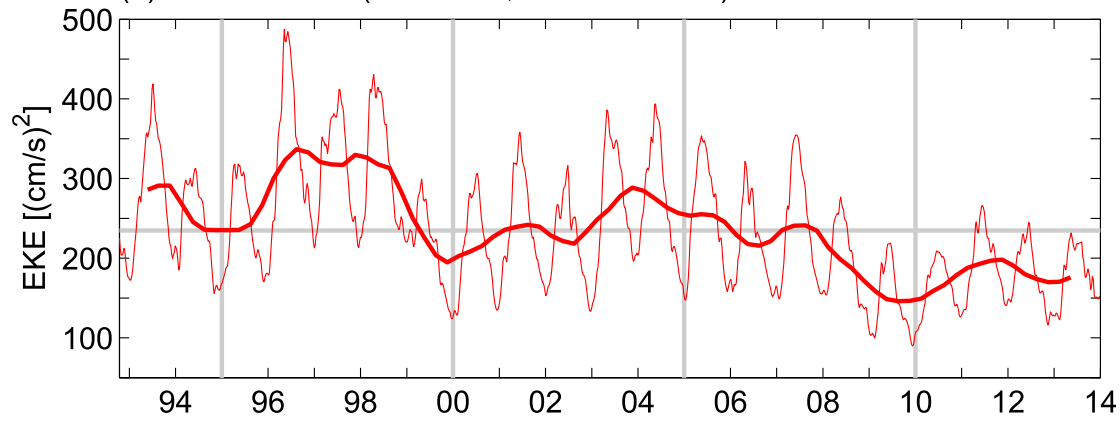

(c) Correlation with PDO Index

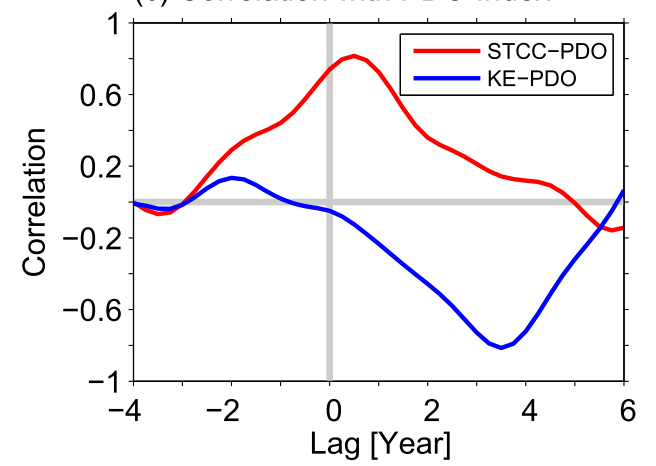

FIG. 11. Time series of EKE from the AVISO SSH anomaly data averaged in (a) the downstream Kuroshio Extension region of $33^{\circ}-37^{\circ} \mathrm{N}, 150^{\circ}-170^{\circ} \mathrm{E}$ and (b) the STCC region of $20^{\circ}-24^{\circ} \mathrm{N}, 140^{\circ} \mathrm{E}-170^{\circ} \mathrm{W}$. Thin lines indicate the original weekly time series and thick lines, the yearly-averaged time series. (c) Lagged correlation between the PDO index and the EKE time series in the downstream Kuroshio Extension region (blue line) and in the STCC region (red line). A positive lag denotes the lead by the PDO index.

Research Project of China 2013CB956201. SK is supported by MEXT through KAKENHI 22106002.

\section{APPENDIX}

\section{Dynamical Processes in the Two-Layer Model}

In the two-layer model ocean, large-scale sea level changes are determined by the barotropic and first-mode baroclinic Rossby wave processes. To clarify these processes explicitly, it is instructive to adopt the quasigeostrophic approximation (Pedlosky 1987) and combine
Eqs. (1)-(4) to form the following linearized vorticity equations:

$$
\begin{gathered}
\frac{\partial}{\partial t}\left(\nabla^{2} \psi_{1}\right)+\beta \frac{\partial \psi_{1}}{\partial x}+\frac{f_{o}^{2}}{g^{\prime} H_{1}} \frac{\partial}{\partial t}\left(\psi_{2}-\psi_{1}\right) \\
=\nabla \times\left(\frac{\tau_{\text {eff }}}{\rho_{1} H_{1}}\right) \text { and } \\
\frac{\partial}{\partial t}\left(\nabla^{2} \psi_{2}\right)+\beta \frac{\partial \psi_{2}}{\partial x}-\frac{f_{o}^{2}}{g^{\prime} H_{2}} \frac{\partial}{\partial t}\left(\psi_{2}-\psi_{1}\right)-\frac{f_{o}}{H_{2}} J\left(\psi_{2}, H_{2}\right)=0,
\end{gathered}
$$


(a) Negative NPGO Index

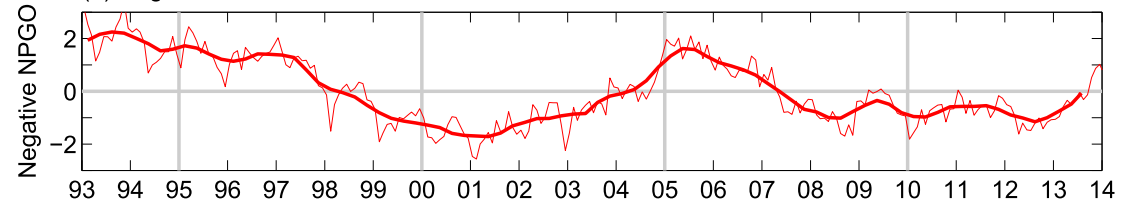

(b) ECMWF Wind Regression to Normalized Negative NPGO: 1993-2013

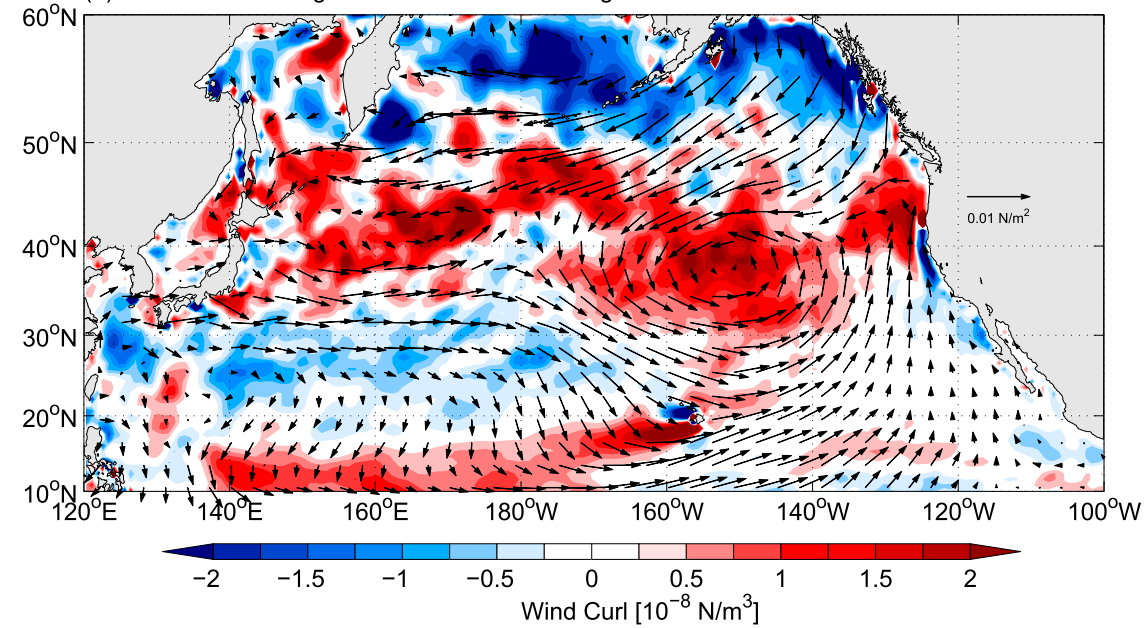

FIG. 12. (a) Time series of negative NPGO index from http://eros.eas.gatech.edu/npgo/data/ NPGO.txt. Thin line denotes the original monthly time series and thick line, the yearly-average time series. (b) Surface wind stress vectors and wind curl (in color) regressed to the annually averaged negative NPGO time series.

where $\psi_{n}$ is the $n$th layer perturbation streamfunction and is related to $h_{n}$ by $\psi_{1}=g h_{1} / f_{o}$ and $\psi_{2}=\left(g h_{1}+\right.$ $\left.g^{\prime} h_{2}\right) / f_{o}, f_{o}$ is the Coriolis parameter at the reference latitude, $\beta$ is the meridional gradient of $f$, and $J$ is the Jacobian operator. In Eq. (A1), the "effective" wind stress

$$
\boldsymbol{\tau}_{\text {eff }}=\boldsymbol{\tau}-\rho_{1} H_{1} \mathbf{u}_{s}^{\prime} \cdot \nabla \mathbf{u}_{s}^{\prime}
$$

includes the eddy momentum fluxes imposed to the upper layer of the model. Notice that the sea level signal $h_{1}$ can be split into those dictated by the baroclinic and barotropic processes, respectively,

$$
h_{1} \equiv h_{\mathrm{bc}}+h_{\mathrm{bt}},
$$

where $h_{\mathrm{bc}}$ and $h_{\mathrm{bt}}$ are related to $\psi_{n}$ by definition:

$h_{\mathrm{bc}} \equiv \frac{f_{o}}{g} \frac{H_{2}\left(\psi_{1}-\psi_{2}\right)}{H_{1}+H_{2}} \quad$ and $\quad h_{\mathrm{bt}} \equiv \frac{f_{o}}{g}\left(\frac{H_{1} \psi_{1}+H_{2} \psi_{2}}{H_{1}+H_{2}}\right)$

Replacing $h_{\mathrm{bc}}$ and $h_{\mathrm{bt}}$ for $\psi_{n}$ in Eqs. (A1) and (A2) leads to the following equations governing the evolution of baroclinic and barotropic sea level signals:

$$
\begin{aligned}
& \frac{\partial}{\partial t}\left(\nabla^{2} h_{\mathrm{bc}}-\frac{f_{o}^{2}}{g^{\prime} H_{e}} h_{\mathrm{bc}}\right)+\beta \frac{\partial h_{\mathrm{bc}}}{\partial x}+\frac{f_{o}^{2}}{g\left(H_{1}+H_{2}\right)} J\left(\psi_{2}, H_{2}\right) \\
& =\frac{f_{o} H_{e}}{g H_{1}} \nabla \times\left(\frac{\tau_{\mathrm{eff}}}{\rho_{1} H_{1}}\right) \text { and } \\
& \frac{\partial}{\partial t}\left(\nabla^{2} h_{\mathrm{bt}}\right)+\beta \frac{\partial h_{\mathrm{bt}}}{\partial x}-\frac{f_{o}^{2}}{g\left(H_{1}+H_{2}\right)} J\left(\psi_{2}, H_{2}\right) \\
& \quad=\frac{f_{o} H_{e}}{g H_{2}} \nabla \times\left(\frac{\tau_{\mathrm{eff}}}{\rho_{1} H_{1}}\right),
\end{aligned}
$$

where $H_{e}=H_{1} H_{2} /\left(H_{1}+H_{2}\right)$ is the equivalent depth.

Notice that the baroclinic sea level signal in Eq. (A6) is dependent on $g^{\prime}$ : a strong (weak) stratification works to enhance (lessen) the forced $h_{\mathrm{bc}}$ responses. For the eddy-induced sea level variability, it is important to note that as the wind stress forcing can deform the layer thicknesses, the eddy-induced sea level responses can differ from those in the model that is solely eddy forced. In other words, the windand eddy-forced sea level changes are not linearly additive in the approach adopted in this study. 


\section{REFERENCES}

Bindoff, N. L., and Coauthors, 2007: Observations: Oceanic climate change and sea level. Climate Change 2007: The Physical Science Basis, S. Solomon et al., Eds., Cambridge University Press, 385-432.

Bromirski, P. D., A. J. Miller, R. E. Flick, and G. Auad, 2011: Dynamical suppression of sea level rise along the Pacific coast of North America: Indications for imminent acceleration. J. Geophys. Res., 116, C07005, doi:10.1029/2010JC006759.

Cazenave, A., and W. Llovel, 2010: Contemporary sea level rise. Annu. Rev. Mar. Sci., 2, 145-173, doi:10.1146/ annurev-marine-120308-081105.

Ceballos, L., E. Di Lorenzo, C. D. Hoyos, N. Schneider, and B. Taguchi, 2009: North Pacific Gyre oscillation synchronizes climate variability in the eastern and western boundary current systems. J. Climate, 22, 5163-5174, doi:10.1175/2009JCLI2848.1.

Chelton, D. B., M. G. Schlax, and R. M. Samelson, 2011: Global observations of nonlinear mesoscale eddies. Prog. Oceanogr., 91, 167-216, doi:10.1016/j.pocean.2011.01.002.

Church, J. A., and Coauthors, 2013: Sea level change. Climate Change 2013: The Physical Science Basis, T. F. Stoker et al., Eds., Cambridge University Press, 1137-1216.

Cummins, P. F., and G. S. E. Lagerloef, 2004: Wind-driven interannual variability over the northeast Pacific Ocean. DeepSea Res., 51, 2105-2121, doi:10.1016/j.dsr.2004.08.004.

Dee, D. P., and Coauthors, 2011: The ERA-Interim reanalysis: Configuration and performance of the data assimilation system. Quart. J. Roy. Meteor. Soc., 137, 553-597, doi:10.1002/ qj.828.

Di Lorenzo, E., and Coauthors, 2008: North Pacific Gyre Oscillation links ocean climate and ecosystem change. Geophys. Res. Lett., 35, L08607, doi:10.1029/2007GL032838.

Ducet, N., P.-Y. Le Traon, and G. Reverdin, 2000: Global highresolution mapping of ocean circulation from TOPEX/Poseidon and ERS-1 and -2. J. Geophys. Res., 105, 19477-19498, doi:10.1029/2000JC900063.

Feng, M., M. J. McPhaden, and T. Lee, 2010: Decadal variability of the Pacific subtropical cells and their influence on the southeast Indian Ocean. Geophys. Res. Lett., 37, L09606, doi:10.1029/2010GL042796.

Greatbatch, R. J., X. Zhai, M. Claus, L. Czeschel, and W. Rath, 2010a: Transport driven by eddy momentum fluxes in the Gulf Stream Extension region. Geophys. Res. Lett., 37, L24401, doi:10.1029/2010GL045473.

$\longrightarrow, \ldots$, J.-D. Kolmann, and L. Czeschel, 2010b: Ocean eddy momentum fluxes at the latitudes of the Gulf Stream and the Kuroshio extensions as revealed by satellite data. Ocean Dyn., 60, 617-628, doi:10.1007/s10236-010-0282-6.

Hallberg, R., 1997: Stable split time stepping schemes for large-scale ocean modeling. J. Comput. Phys., 135, 54-65, doi:10.1006/ jcph.1997.5734.

Hurlburt, H. E., A. J. Wallcraft, W. J. Schmitz, P. J. Hogan, and E. J. Metzger, 1996: Dynamics of the Kuroshio/Oyashio current system using eddy-resolving models of the North Pacific Ocean. J. Geophys. Res., 101, 941-976, doi:10.1029/95JC01674.

Jayne, S. R., N. G. Hogg, and P. Malanotte-Rizzoli, 1996: Recirculation gyres forced by a beta-plane jet. J. Phys. Oceanogr., 26, 492-504, doi:10.1175/1520-0485(1996)026<0492: RGFBAB $>2.0 . \mathrm{CO} ; 2$.

, and Coauthors, 2009: The Kuroshio Extension and its recirculation gyres. Deep-Sea Res., 56, 2088-2099, doi:10.1016/ j.dsr.2009.08.006.
Kessler, W. S., 1990: Observations of long Rossby waves in the northern tropical Pacific. J. Geophys. Res., 95, 5183-5217, doi:10.1029/JC095iC04p05183.

Kobashi, F., and H. Kawamura, 2002: Seasonal variation and instability nature of the North Pacific Subtropical Countercurrent and the Hawaiian Lee Countercurrent. J. Geophys. Res., 107, C03185, doi:10.1029/2001JC001225.

Köhl, A., and D. Stammer, 2008: Decadal sea level changes in the 50-year GECCO ocean synthesis. J. Climate, 21, 1876-1890, doi:10.1175/2007JCLI2081.1.

Mantua, N. J., S. R. Hare, Y. Zhang, J. M. Wallace, and R. C. Francis, 1997: A Pacific interdecadal climate oscillation with impacts on salmon production. Bull. Amer. Meteor. Soc., 78, 1069-1079, doi:10.1175/1520-0477(1997)078<1069:APICOW>2.0.CO;2.

Merrifield, M. A., and M. E. Maltrud, 2011: Regional sea level trends due to a Pacific trade wind intensification. Geophys. Res. Lett., 38, L21605, doi:10.1029/2011GL049576.

Nakano, H., and I. Ishikawa, 2010: Meridional shift of the Kuroshio Extension induced by response of recirculation gyre to decadal wind variations. Deep-Sea Res. II, 57, 1111-1126, doi:10.1016/j.dsr2.2009.12.002.

Pedlosky, J., 1987: Geophysical Fluid Dynamics. Springer-Verlag, $710 \mathrm{pp}$.

Penduff, T., and Coauthors, 2011: Sea level expression of intrinsic and forced ocean variabilities at interannual time scales. J. Climate, 24, 5652-5670, doi:10.1175/JCLI-D-11-00077.1.

Pierini, S., 2014: Kuroshio Extension bimodality and the North Pacific Oscillation: A case of intrinsic variability paced by external forcing. J. Climate, 27, 448-454, doi:10.1175/ JCLI-D-13-00306.1.

Qiu, B., 1999: Seasonal eddy field modulation of the North Pacific Subtropical Countercurrent: TOPEX/Poseidon observations and theory. J. Phys. Oceanogr., 29, 2471-2486, doi:10.1175/ 1520-0485(1999)029<2471:SEFMOT >2.0.CO;2.

_ 2002: Large-scale variability in the midlatitude subtropical and subpolar North Pacific Ocean: Observations and causes. J. Phys. Oceanogr., 32, 353-375, doi:10.1175/1520-0485(2002)032<0353: LSVITM $>2.0 . \mathrm{CO} ; 2$.

_ 2003: Kuroshio Extension variability and forcing of the $\mathrm{Pa}-$ cific decadal oscillations: Responses and potential feedback. J. Phys. Oceanogr., 33, 2465-2482, doi:10.1175/2459.1.

_ , and S. Chen, 2005: Variability of the Kuroshio Extension jet, recirculation gyre, and mesoscale eddies on decadal timescales. J. Phys. Oceanogr., 35, 2090-2103, doi:10.1175/JPO2807.1.

— and - 2010a: Eddy-mean flow interaction in the decadally modulating Kuroshio Extension system. Deep-Sea Res. II, 57, 1098-1110, doi:10.1016/j.dsr2.2008.11.036.

$\longrightarrow$, and $-2010 \mathrm{~b}$ : Interannual-to-decadal variability in the bifurcation of the North Equatorial Current off the Philippines. J. Phys. Oceanogr., 40, 2525-2538, doi:10.1175/2010JPO4462.1.

— eddy variability on the modification of North Pacific Intermediate Water. J. Phys. Oceanogr., 41, 503-515, doi:10.1175/ 2010JPO4575.1.

— variability in the northwestern tropical Pacific Ocean. J. Phys. Oceanogr., 42, 193-206, doi:10.1175/JPO-D-11-061.1.

$\longrightarrow$, and - 2013: Concurrent decadal mesoscale eddy modulations in the western North Pacific subtropical gyre. J. Phys. Oceanogr., 43, 344-358, doi:10.1175/JPO-D-12-0133.1.

,$- \ldots$, and P. Hacker, 2004: Synoptic-scale air-sea flux forcing in the western North Pacific: Observations and their impact on 
SST and the mixed layer. J. Phys. Oceanogr., 34, 2148-2159, doi:10.1175/1520-0485(2004)034<2148:SAFFIT >2.0.CO;2.

,,,--- N. Hogg, S. Jayne, and H. Sasaki, 2008: The Kuroshio Extension northern recirculation gyre: Profiling float measurements and forcing mechanism. J. Phys. Oceanogr., 38, 1764-1779, doi:10.1175/2008JPO3921.1.

Rhines, P. B., and W. R. Holland, 1979: A theoretical discussion of eddy-driven mean flows. Dyn. Atmos. Oceans, 3, 289-325, doi:10.1016/0377-0265(79)90015-0.

Rio, M. H., S. Guinehut, and G. Larnicol, 2011: New CNES-CLS09 global mean dynamic topography computed from the combination of GRACE data, altimetry, and in-situ measurements. J. Geophys. Res., 116, C07018, doi:10.1029/2010JC006505.

Sasaki, Y. N., S. Minobe, and Y. Miura, 2014: Decadal sea-level variability along the coast of Japan in response to ocean circulation changes. J. Geophys. Res., 119, 266-275, doi:10.1002/ 2013JC009327.

Smith, W. H. F., and D. Sandwell, 1997: Global seafloor topography from satellite altimetry and ship depth soundings. Science, 277, 1956-1962, doi:10.1126/science.277.5334.1956.

Stammer, D., A. Cazenave, R. M. Ponte, and M. E. Tamisiea, 2013: Causes for contemporary regional sea level changes. Annu. Rev. Mar. Sci., 5, 21-46, doi:10.1146/annurev-marine-121211-172406.

Taguchi, B., S.-P. Xie, N. Schneider, M. Nonaka, H. Sasaki, and Y. Sasai, 2007: Decadal variability of the Kuroshio Extension:
Observations and an eddy-resolving model hindcast. $J$. Climate, 20, 2357-2377, doi:10.1175/JCLI4142.1.

B. Qiu, M. Nonaka, H. Sasaki, S.-P. Xie, and N. Schneider, 2010: Decadal variability of the Kuroshio Extension: Mesoscale eddies and recirculation. Ocean Dyn., 60, 673-691, doi:10.1007/s10236-010-0295-1.

Timmermann, A., S. McGregor, and F.-F. Jin, 2010: Wind effects on the past and future regional sea level trends in the southern Indo-Pacific. J. Climate, 23, 4429-4437, doi:10.1175/ 2010JCLI3519.1.

Waterman, S., and S. R. Jayne, 2011: Eddy-mean flow interactions in the along-stream development of a western boundary current jet: An idealized model study. J. Phys. Oceanogr., 41, 682707, doi:10.1175/2010JPO4477.1.

— N. G. Hogg, and S. R. Jayne, 2011: Eddy-mean flow interaction in the Kuroshio Extension region. J. Phys. Oceanogr., 41, 1182-1208, doi:10.1175/2010JPO4564.1.

Yasuda, T., and K. Sakurai, 2006: Interdecadal variability of the sea surface height around Japan. Geophys. Res. Lett., 33, L01605, doi:10.1029/2005GL024920.

Yoshida, S., B. Qiu, and P. Hacker, 2011: Low-frequency eddy modulations in the Hawaiian Lee Countercurrent: Observations and connection to the Pacific decadal oscillation. J. Geophys. Res., 116, C12009, doi:10.1029/ 2011JC007286. 